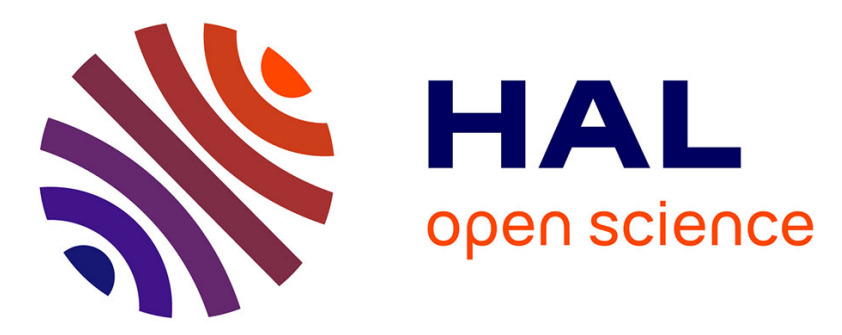

\title{
Ypp1/YGR198w plays an essential role in phosphoinositide signalling at the plasma membrane
}

Chao Zhai, Kuoyu Li, Valentini Markaki, John P Phelan, Katherine Bowers, Frank T Cooke, Barry Panaretou

\section{- To cite this version:}

Chao Zhai, Kuoyu Li, Valentini Markaki, John P Phelan, Katherine Bowers, et al.. Ypp1/YGR198w plays an essential role in phosphoinositide signalling at the plasma membrane. Biochemical Journal, 2008, 415 (3), pp.455-466. 10.1042/BJ20080209 . hal-00478962

\section{HAL Id: hal-00478962 https://hal.science/hal-00478962}

Submitted on 30 Apr 2010

HAL is a multi-disciplinary open access archive for the deposit and dissemination of scientific research documents, whether they are published or not. The documents may come from teaching and research institutions in France or abroad, or from public or private research centers.
L'archive ouverte pluridisciplinaire HAL, est destinée au dépôt et à la diffusion de documents scientifiques de niveau recherche, publiés ou non, émanant des établissements d'enseignement et de recherche français ou étrangers, des laboratoires publics ou privés. 


\title{
Ypp1/YGR198w plays an essential role in phosphoinositide signalling at the plasma membrane.
}

\author{
Chao Zhai*, Kuoyu Li*, Valentini Markaki*, John P. Phelan ${ }^{\dagger}$, Katherine Bowers ${ }^{\dagger}$, Frank \\ T. Cooke ${ }^{\dagger}$, and Barry Panaretou* ${ }^{*}$
}

*Pharmaceutical Science Division, King's College London, Franklin-Wilkins Building, 150 Stamford Street, London SE1 9NH, United Kingdom; ${ }^{\dagger}$ Institute of Structural and Molecular Biology, Division of Bioscience, University College London, Gower Street, London WC1E 6BT, United Kingdom

\footnotetext{
"To whom correspondence should be addressed: Tel: (44) (0) 207 848-4003, Fax: (44) (0) 207 848-4500, Email: barry.panaretou@kcl.ac.uk
}

Key words: Signalling, phosphoinositide, lipid kinase, Saccharomyces cerevisiae

Short page-heading title: Ypp1 in cell surface signalling

Abbreviations used: PtdIns, phosphatidylinositol; 3-AT, 3-aminotriazole

\section{SYNOPSIS}

Phosphoinositide signalling through the eukaryotic plasma membrane makes essential contributions to many processes, including re-modelling of the actin cytoskeleton, vesicle trafficking and signalling from the cell surface. A proteome-wide screen performed in Saccharomyces cerevisiae revealed that Yppl physically interacts with the plasma-membrane associated phosphatidylinositol 4-kinase Stt4. Here we demonstrate that phenotypes of yppl and stt4 conditional mutants are identical, namely osmoremedial temperature sensitivity, hypersensitivity to cell wall destabilizers and defective organization of actin. We go on to show that overexpression of STT4 suppresses the temperature sensitive growth defect of ypp 1 mutants. In contrast, overexpression of genes encoding the other two phosphatidylinositol 4-kinases in yeast, Pik1 and Lsb6, do not suppress this phenotype. This implies a role for Ypp1 in Stt4dependant events at the plasma membrane, as opposed to a general role in overall metabolism of phosphatidylinositol 4-phosphate. Use of a pleckstrin homology domain sensor reveals there are substantially less plasma membrane associated 4-phosphorylated phosphoinositides in yppl mutants, in comparison to wild-type cells. Furthermore, in vivo labelling with $\left[{ }^{3} \mathrm{H}\right]$ inositol indicates a dramatic reduction in the level of phosphatidylinositol 4-phosphate in yppl mutants. This is the principal cause of lethality at non-permissive conditions in yppl mutants, as limiting the activity of the Sac1 phosphatidylinositol 4-phosphate phosphatase leads to restoration of viability. Additionally, the endocytic defect associated with elevated levels of phosphatidylinositol 4-phosphate in sac1 $\Delta$ cells is restored in combination with a yppl mutant, consistent with the opposing effects these two mutations have on levels of this phosphoinositide. 


\section{INTRODUCTION}

Polyphosphoinositide second messengers regulate numerous cellular processes in eukaryotes, including organization of the actin cytoskeleton, vesicle trafficking and signalling via MAP kinase cascades. There has been significant progress in understanding how the rapid turnover of polyphosphoinositides (PPIn) is controlled both spatially and temporally (reviewed in [1]). Of the seven PPIn species recognized, four have been identified in the budding yeast Saccharomyces cerevisiae. One of these, phosphatidylinositol 4-phosphate (PtdIns $4 P$ ), is synthesized by three distinct and highly conserved phosphatidylinositol 4-kinases: Pik1 [2, 3], Stt4 [4] and Lsb6 [5-7]. Pik1 is found at the Golgi and in the nucleus, Stt4 localizes to the plasma membrane, and Lsb6 is found at the plasma membrane and the vacuolar membrane. Both Stt4 and Pik1 are essential, synthesising a discrete location-specific pool of PtdIns $4 P$. Consequently, deletion of one cannot be compensated by overexpression of the other, even though both proteins catalyse the same biochemical reaction [8]. Lsb6, the third phosphatidylinositol 4-kinase, is non-essential; its contribution to total cellular PtdIns $4 P$ in vegetative cells being uncertain, given that over $90 \%$ of PtdIns $4 P$ is lost in a $s t t 4^{t s} p i k I^{t s}$ double mutant within one hour of shift to the non-permissive temperature [9]. Thus far, the only phenotype observed in $l s b 6 \Delta$ cells is a reduction in endosome motility, an investigation prompted by the interaction of this lipid kinase with Las17 (the yeast orthologue of Wiskott-Aldrich syndrome protein), which is essential for endocytosis. In the $l s b 6 \Delta$ background, expression of a catalytically inactive Lsb6 mutant could restore wild-type levels of endosome motility as effectively as expressing wild-type Lsb6. Therefore, the role played by Lsb6 in endosome motility is independent of its lipid kinase activity [10].

Pik1 localizes to the Golgi, and the PtdIns $4 P$ synthesized by this enzyme is essential for Golgi to plasma membrane vesicular trafficking $[9,11,12]$. In addition, Pik1 shuttles between the cytoplasm and the nucleus. Mutant alleles of PIK1 that restrict location of the protein to membranes of the secretory pathway, do not sustain viability of a pik1 $\Delta$ strain. Therefore, the PtdIns $4 P$ generated in the nucleus by Pik1 is essential for cell viability, though the nuclearspecific role of PtdIns4P remains unknown [13]. Stt4 localizes to the plasma membrane, in part via an interaction with $\mathrm{Sfk} 1$, a membrane spanning protein [14]. The PtdIns $4 P$ pool generated by Stt4 is required for aminophospholipid transport from the endoplasmic reticulum to the Golgi [15], organization of the actin cytoskeleton, maintenance of vacuole morphology [9] and cell wall integrity [14]. Some of these roles are due to PtdIns $4 P$ acting as a precursor for $\operatorname{PtdIns}(4,5) P_{2}$ synthesis which is catalysed by the plasma-membrane associated phosphatidylinositol 4phosphate 5-kinase Mss4 [16]. For instance, plasma membrane $\operatorname{PtdIns}(4,5) P_{2}$ activates the Rho/Pkc1-mediated MAP kinase cascade that maintains cell wall integrity. More specifically, generation of $\operatorname{Ptdn}(4,5) P_{2}$ recruits the guanine nucleotide exchange factor Rom 2 to the plasma membrane via its phosphoinositide PH (pleckstrin homology) binding domain, and is an absolute requirement for activation of the Rho1 GTPase [14].

There has been substantial progress in characterizing mechanisms that terminate PtdIns $4 P$ dependent processes, through identification of lipid phosphatases with enzymatic activity towards phosphoinositides [17], and reviewed in [1]). In contrast, mechanisms that regulate the generation of PtdIns $4 P$ by Stt 4 are poorly defined. Insight into mechanisms that regulate lipid kinases has come from identifying accessory factors. For example, Frq1 and Vps15 are required for both membrane localization and optimal activity of the PtdIns 4-kinase Pik1 and the PtdIns 3-kinase Vps34, respectively [18, 19]. 
Recently, the protein encoded by the essential ORF $Y G R 198 \mathrm{~W}$ was identified as a binding partner of Stt4 [20]. This ORF was recently named YPP1 (sYnuclein-Protective Protein), because it acts as a multi-copy suppressor of the toxic effect of expressing a human alpha-synuclein mutant in yeast [21]. We have tested the possibility that Ypp1 is an accessory factor for Stt4. We characterize the phenotypes of temperature sensitive $(t s)$ mutants of $Y P P 1$, and we show that they are similar to phenotypes associated with stt $4^{t s}$ mutants. Moreover, overexpression of STT4 suppresses the temperature sensitive growth defect of ypp1 mutants. We go on to show that total levels of PtdIns $4 P$, as well as levels of plasma membrane 4-phosphorylated PtdIns, are low in $y p p I^{t s}$ mutants. Together, these data show for the first time that Ypp1 makes an essential contribution to Stt4 dependent production of PtdIns $4 P$ at the plasma membrane.

\section{MATERIALS AND METHODS Strains, plasmids and media.}

Yeast strains used in this study are listed in Table 1. Plasmids are described in the appropriate sections below. Strains were grown in either rich media (YPD) or synthetic minimal media (SD) with appropriate supplements for plasmid maintenance [22]. Gene deletions were performed by replacing the target ORF with $h p h$ (conferring resistance to Hygromycin B), via one step gene replacement, as previously described [23]. Integration at the correct locus was confirmed by PCR using appropriate primers [24].

\section{Isolation of YPP1 conditional alleles.}

The heterozygous YPP1/ypp1 $\Delta$ diploid Y24828 was obtained from EUROSCARF and transformed with a centromeric URA3 S. cerevisiaelEscherichia coli shuttle vector (pYC3P) bearing the YPP1 promoter (a fragment $0.45 \mathrm{~kb}$ upstream of the ATG) fused to the YPP1 ORF (a $2.5 \mathrm{~kb}$ fragment), followed by the $A D H 1$ transcriptional terminator (a $0.4 \mathrm{~kb}$ fragment). The $Y P P 1$ promoter and ORF from this vector were then subcloned into a centromeric LEU 2 S.cerevisiae/Escherichia coli shuttle vector (again bearing the $A D H 1$ terminator), to give pYC1P. Strain Y24828 was transformed with pYC3P and then sporulated, followed by subsequent dissection of tetrads and selection of a ypp $1 \triangle$ haploid (strain ZC0) with viability maintained by the presence of the URA3 vector bearing YPP1 (pYC3P). Mutations in YPP1 were generated by error-prone amplification of the YPP1 ORF using pYC3P as template, as previously described [25]. The oligonucleotide primers were designed so that the 5' primer overlaps the $3^{\prime}$ 'end of the YPP 1 promoter, and the $3^{\prime}$ primer overlaps the 5 ' end of the $A D H 1$ transcriptional terminator (15bp overlaps in both cases). Vectors bearing the mutant yppl alleles were generated by transforming strain ZC0 with a) the mutant ypp 1 PCR products plus b) a large linear fragment from $\mathrm{pYC1P}$ lacking the wild-type YPP1. The two fragments recombine with each other in vivo, owing to the $15 \mathrm{bp}$ overlaps between them. The transformants, selected on SD media lacking both leucine and uracil, possess the pYC3P URA3 vector bearing wild-type YPP1, and a $L E U 2$ vector bearing mutated $y p p 1$. More than 4000 transformants were picked and incubated overnight at $25^{\circ} \mathrm{C}$ in 384 well plates containing SD lacking leucine. Those transformants bearing $t s$ mutants of $y p p 1$ were isolated as described previously [26]. To ensure these $t s$ phenotypes were attributed to mutated $y p p 1$, plasmids from the strains were recovered, transformed into the ZC0 strain and rescreened for the ts phenotype. In this way, a series of isogenic ypp $1 \Delta$ haploid strains were generated, possessing vector-borne copies of wild-type YPP1 (ZC1, Table 1) or ypp $1^{\text {ts }}$ alleles (ZC2-8, Table 1). The coding regions of $y p p 1^{t s}$ mutants were sequenced.

\section{Sensitivity to cell wall damaging agents.}


Exponentially growing cultures were adjusted to equal cell density $\left(1 \times 10^{7}\right.$ cells $\left./ \mathrm{ml}\right)$ and four successive sixfold serial dilutions were spotted on YPD, or YPD containing the desired concentration of sorbitol, caffeine or SDS. The plates were incubated at the temperatures specified in figure legends.

\section{$\left[{ }^{3} \mathrm{H}\right]$ inositol labeling of S.cerevisiae and extraction of labeled phosphoinositides.}

Phosphoinositides were labeled in vivo as previously described [27]. Briefly, strains were grown at $25^{\circ} \mathrm{C}$ in SD medium without inositol plus appropriate supplements, in the presence of $15 \mu \mathrm{Ci} / \mathrm{ml}$ $\left[{ }^{3} \mathrm{H}\right]$ inositol (GE Healthcare). Once cultures had reached exponential phase, they were split into two aliquots; one was incubated for a further hour at $25^{\circ} \mathrm{C}$, the other was shifted to $37^{\circ} \mathrm{C}$ for 1 hour. Cells were killed by an equal volume of ice-cold methanol, and sedimented $(3000 \mathrm{xg}, 5$ minutes at $4^{0} \mathrm{C}$ ). Lipids were extracted, and then deacylated, followed by recovery of the glycerophosphoinositols that were resolved by anion-exchange HPLC on a Partisphere 5-SAX column (Whatman).

\section{Assessing multicopy suppression by selected ORFs.}

Candidate ORFs were overexpressed from the vector pY195M, which is a modification of the episomal URA3 vector YEplac195 [28]. The vector bears the MET25 inducible promoter and the transcription terminator from $P G K 1$. Candidate ORFs were amplified from S.cerevisiae genomic DNA and ligated into pY195M. The resulting vectors were transformed into the ZC1 strain, and isogenic strains containing vector borne $y p p I^{t s}$ alleles. Transformants were transferred to SD plates lacking uracil, leucine and methionine, to induce over-expression of the candidate ORF.

\section{Two-hybrid analysis.}

The YPPI and STT4 ORFs were amplified from yeast genomic DNA, including appropriate restriction sites in the oligonucleotides. The YPPI PCR product was subcloned into pGAD-C1 [29] to give pAD-YPP1; STT4 was cloned into pGBDU-C1 [29] to give pBD-STT4. Vectors pAD-YPP1 and pBD-STT4 were transformed into strains PJ69-4a and PJ69-4 $\alpha$, respectively [29]. Transformants ( $\mathrm{a}$ and $\alpha$ ) were mated on YPD for $8 \mathrm{~h}$ at $30^{\circ} \mathrm{C}$, and then diploids selected on SD lacking both leucine and uracil. To assess Stt4/Ypp1 interaction, the diploids were innoculated onto SD lacking leucine, uracil and histidine, and in the presence of $1 \mathrm{mM} \mathrm{3-AT}$ (Sigma).

\section{Assessing the activation state of the MAPK cell wall integrity pathway.}

Exponentially growing cultures were either heat shocked or treated with $10 \mathrm{mM}$ caffeine (as specified in figure legends). Preparation of total yeast protein extracts was as described previously [30]. Western blots were probed with either a) anti-(Thr202/Tyr204)-p44/42 MAP kinase antiserum (New England Biolabs) which specifically recognizes the dually Thr190/Tyr 192-phosphorylated (activated) Slt2 in yeast, or b) anti-Slt2 (Santa Cruz). Activity of Rlm1 transcription factor activity was assessed using p2-RLM1 a YIL117c promoter-LacZ reporter plasmid [31].

\section{Localization of actin and 4-phosphorylated PtdIns.}

Cells were grown to mid-logarithmic phase at $25^{\circ} \mathrm{C}$, followed by further incubation at $25^{\circ} \mathrm{C}$ or upshift to $37^{\circ} \mathrm{C}$, then fixed in formaldehyde and stained with rhodamine-phalloidin (Molecular 
Probes) to visualize actin [32]. The cellular distribution of 4-phosphorylated PtdIns was assessed by transforming strains with pTL511, a centromeric URA3 plasmid expressing a tandem dimer of the PH domain of Osh2 fused to green fluorescent protein (GFP), under control of the constitutively active $\mathrm{PHO} 5$ promoter [33]. Prior to observation by fluorescence microscopy, exponential phase cells were either maintained at $25^{\circ} \mathrm{C}$ or shifted to a strongly non-permissive temperature $\left(39^{\circ} \mathrm{C}\right)$ for 15 minutes, as described previously [33].

\section{Endocytosis of Ste3-GFP and Fui1-GFP.}

Strains were transformed with pFL38GalFUI1-GFP, a centromeric URA3 vector that enables galactose inducible synthesis of an Fuil-GFP fusion [34]. For localization of Fuil-GFP, cells were grown to exponential phase in $2 \%$ galactose and $0.02 \%$ glucose at $25^{\circ} \mathrm{C}$, to induce synthesis of Fuil-GFP. This was followed by addition of $2 \%$ glucose, to repress Fuil-GFP synthesis. Cells were then maintained at $25^{\circ} \mathrm{C}$ or shifted to $37^{\circ} \mathrm{C}$ for thirty minutes, followed by addition of uridine $(80 \mu \mathrm{g} / \mathrm{ml})$ to induce endocytosis. Samples were removed for observation at the intervals described in figure legends, and endocytosis was stopped by adding ice-cold energy poisoning buffer (SD media without carbon source, $10 \mathrm{mM} \mathrm{NaF}, 10 \mathrm{mM} \mathrm{NaN}_{3}$ ) as previously described [35]. GFP fusions were visualized by fluorescence microscopy.

\section{RESULTS}

\section{Isolation of $y p p 1^{t s}$ alleles.}

To determine the function of Ypp1, we generated conditional lethal alleles by PCR-mediated mutagenesis. Seven $y p p 1^{t s}$ mutants were isolated, three of which exhibited moderate growth at $37^{\circ} \mathrm{C}$, with the remaining four displaying no growth at all at this temperature (Fig. 1A). Three of the latter, exhibiting a robust $t s$ phenotype, were selected for further work and the Ypp1 coding regions were sequenced. Most error-prone PCR techniques are not truly random as they yield more transitions than transversions. The method we used however, removes the bias [25]. The amino acid substitutions were: ypp I-35 $5^{t s}$ G60R, N79I, N102S, E189A, L220P, K329R and S336P; ypp1-39 $9^{t s}$ P2A, K197E, F218L, L442S, L453P and C463R; and ypp 1-41 $1^{t s} \mathrm{~F} 343 \mathrm{~V}, \mathrm{~V} 538 \mathrm{M}$, W571R, K577E, I584V, K656E and S678L.

\section{Phenotypes of $y p p 1^{t s}$ mutants are similar to those displayed by $s t 4^{t s}$ and $m s s 4^{t s}$ mutants.}

The PtdIns(4,5) $P_{2}$ generated by $\mathrm{Stt} 4$ and Mss4 plays an essential role in the cell wall integrity pathway; inactivation of either kinase leads to cell lysis $[9,16]$. As a result, the lack of growth displayed by $s t 4^{t s}$ cells at $37^{\circ} \mathrm{C}$ is suppressed in the presence of $1 \mathrm{M}$ sorbitol [14], a property shared by all seven ypp $1^{t s}$ mutants (Fig. 1A), albeit to a varying extent. This osmoremedial phenotype is displayed clearly by six of the mutants, and is poorly displayed (but still detectable) by ypp 1-35 $5^{t s}$ (Fig. 1A).

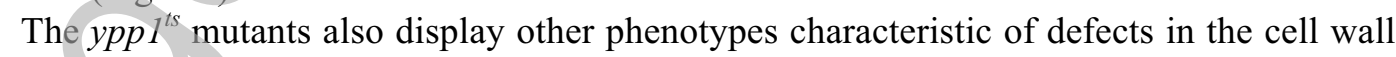
integrity MAP kinase cascade, namely caffeine sensitivity, which can be suppressed in the presence of an osmotic stabilizer such as sorbitol, and sensitivity to low levels of SDS (Fig. 1B). Of the three mutants tested, ypp $1-35^{t s}$ was the most sensitive to caffeine and SDS. This was expected, because this mutant displayed a robust temperature sensitive phenotype, which was poorly suppressed by osmotic stabilization of media (Fig. 1A).

Plasma membrane phosphoinositides generated by the sequential action of Stt4 and Mss4 have also been implicated in the organization of the actin cytoskeleton. In the wild-type, actin 
distribution is polarized, as indicated by the concentration of cortical actin in the bud (Fig. 2). A shift from $25^{\circ} \mathrm{C}$ to $37^{\circ} \mathrm{C}$ degrees causes a heat-induced disorganization of the actin cytoskeleton, which is transient in the wild-type, persisting for upto 2 hours, followed by recovery in organization of the cytoskeleton. In contrast to wild-type cells, however, this disturbance in actin organization persisted for at least 3 hours after temperature upshift in $y p p 1^{t s}$ mutants, with random cortical actin patches evident throughout both mother and daughter cells (Fig. 2). Such irregular organization of actin was even noticeable at permissive temperature in the ypp $1-35^{t s}$ mutant (Fig. 2). An identical phenotype is displayed by both $s t t 4^{t s}$ and $m s s 4^{t s}$ mutants $[9,16]$.

\section{STT4 is a multicopy suppressor of $y p p 1^{t s}$.}

Overexpression of the PtdIns 4-kinase encoded by STT4 is sufficient to restore growth of ypp 1$39^{t s}$ and $y p p 1-41^{t s}$ at $37^{\circ} \mathrm{C}$ (Fig. 3). This confirms the possibility of biological interaction between these two proteins inferred by both their physical interaction [20], and the similarities in phenotypes that arise when function of either protein is compromised. Growth of $y p p 1-35^{t s}$ at $37^{\circ} \mathrm{C}$, however, was not restored. This is probably due to the extent to which Ypp1 function is compromised in this mutant; of the three mutants tested, $y p p 1-35^{t s}$ was the most sensitive to SDS and caffeine (Fig. 1B), and temperature sensitivity was barely suppressed by osmotic stabilization (Fig. 1A). In S.cerevisiae there is one other essential PtdIns 4-kinase, the Golgi-localized Pik1. Even though Stt4 and Pik1 both produce the same second messenger, deletion of one kinase cannot be rescued by overexpression of the other because the enzymes synthesize essential pools of PtdIns $4 P$ on different intracellular membranes, and PtdIns $4 P$ is not freely diffusible through the cell [8]. At $37^{\circ} \mathrm{C}$, the ypp $1-39^{t s}$ and ypp $1-41^{t s}$ mutants were rescued by overexpressing STT4, but not by PIK1 (Fig. 3) or by LSB6, the third PtdIns 4-kinase in S. cerevisiae (not shown). This implies a role for Ypp1 in Stt4-dependant events at the plasma membrane, as opposed to a general role in overall metabolism of PtdIns $4 P$. Growth at $37^{\circ} \mathrm{C}$ was not restored in any of the mutants when the phosphatidylinositol 4-phosphate 5-kinase Mss4 was over-expressed (not shown). Rescue by Stt4 overexpression implies that levels of PtdIns $4 P$ are too low to support viability of $y p p 1^{t s}$ mutants at $37^{\circ} \mathrm{C}$.

The physical interaction between Stt4 and Ypp1 was first identified by affinity captureMS [20]. We confirmed this by the yeast-two hybrid interaction trap, using a BD-Stt4 fusion as bait and an AD-Ypp1 fusion as prey (Fig. 4A). Furthermore, the interaction between wild-type Ypp1 and Stt4 is weakened at high temperature (Fig. 4A and Fig. 4B), as evidenced by the slower growth rate at $37^{\circ} \mathrm{C}$ versus $25^{\circ} \mathrm{C}$, on media that select for Ypp1-Stt4 interaction. In addition we went on to show that interaction between Stt 4 and the ypp1-35 $5^{\text {ts }}, y p p 1-39^{\text {ts }}$ and ypp1-41 $1^{\text {ts }}$ mutants, was lost at $37^{\circ} \mathrm{C}$. Indeed, the interaction between these mutant proteins and Stt4 was so destabilized, that it could not be detected even at $25^{\circ} \mathrm{C}$ (Fig. 4A). We anticipated, however, that interaction at $25^{\circ} \mathrm{C}$ might be displayed between $\mathrm{Stt} 4$ and one of the less robust $t s$ mutants, such as ypp1-30 $0^{\text {ts }}$ (Fig.1A). This was found to be the case, as a weak interaction between Stt4 and ypp1$30^{\text {ts }}$ was detectable at $25^{\circ} \mathrm{C}$ (Fig. $4 \mathrm{~B}$ ).

\section{At the restrictive temperature, $y p p 1^{t s}$ cells display diminished levels of plasma membrane- associated 4-phosphorylated PtdIns.}

Cells lacking genomic YPP1 but expressing wild-type or mutant yppl were transformed with a vector expressing a GFP-PH ${ }^{\text {Osh2 }}$ dimer. The pleckstrin homology $(\mathrm{PH})$ domain of Osh2 specifically recognizes PtdIns $4 P$ and PtdIns $(4,5) P_{2}$ and lacks an accessory site that would lead to association with a specific cellular membrane, allowing it to be exploited as an unbiased reporter for Ptdins $4 P$ and PtdIns $(4,5) P_{2}$ [33]. In wild-type cells, at both $25^{\circ} \mathrm{C}$ and $39^{\circ} \mathrm{C}$, this reporter localized to both punctate internal structures and the plasma membrane (Fig. 5A), in agreement with previously reported localization for this sensor [33]. In the ypp 1-41 $1^{t s}$ mutant, however, 15 
minutes incubation at $39^{\circ} \mathrm{C}$ led to a rapid loss of plasma membrane localization of the reporter. The effect was even more severe in $y p p 1-35^{t s}$ cells, as GFP-PH ${ }^{\text {Osh2 }}$ dimer localization at the plasma membrane was significantly reduced even at permissive temperature (Fig. 5A).

\section{At the restrictive temperature, $y p p 1-41^{t s}$ cells display diminished levels of PtdIns4P.}

Wild-type and ypp 1-41 $1^{\text {ts }}$ cells were incubated with $\left[^{3} \mathrm{H}\right]$ inositol at $25^{\circ} \mathrm{C}$ for upto 6 generation times, to label all inositol-based lipids to near steady-state equilibrium. These exponential-phase cultures were split in two, with one aliquot shifted to $37^{\circ} \mathrm{C}$ for 1 hour, and the other maintained at $25^{\circ} \mathrm{C}$. Subsequent analysis of labelled lipids by HPLC allowed us to follow the levels of glycerolphosphoinositols derived from all four PPIns made by S.cerevisiae. As expected, levels of PtdIns $(3,5) P_{2}$ were almost identical in mutant and wild-type cells (Fig. 5B).

At the permissive temperature, the level of PtdIns $4 P$ in ypp $1-41^{t s}$ cells was almost $60 \%$ lower than that seen in wild-type cells (Fig. 5B). A shift to $37^{\circ} \mathrm{C}$ for one hour led to a $50 \%$ decline in PtdIns $4 P$ in the wild-type. Under these conditions the level of Ptdins $4 P$ in $y p p 1-41^{t s}$ did not fall appreciably in comparison to levels in ypp $1-41^{t s}$ at $25^{\circ} \mathrm{C}$, though levels of PtdIns $4 P$ in this mutant were already low prior to the upshift in temperature.

The changes in PtdIns4P are reflected by the in vivo protein-protein interaction data because the interaction between the Stt4 lipid kinase and wild-type Ypp1 is weaker at high temperature (Fig. 4A and Fig. 4B). If Ypp1 is required for optimal function of Stt4, then an upshift in temperature (diminishing the interaction between the two proteins) would account for the drop in synthesis of PtdIns $4 P$ observed at $37^{\circ} \mathrm{C}$ in wild-type cells (Fig. 5B). A consequence of reduced interaction between wild-type Ypp1 and Stt4 would mean that the effect of mutant Ypp1 on Stt4 function would be less noticeable at $37^{\circ} \mathrm{C}$ than at $25^{\circ} \mathrm{C}$. This explains why, at $37^{\circ} \mathrm{C}$, levels of PtdIns $4 P$ are only slightly lower in the ypp $1-41^{t s}$ mutant than they are in the wild-type.

Levels of PtdIns $(4,5) P_{2}$ were lower in ypp $1-41^{\text {ts }}$ cells relative to the wild-type, at both permissive and non-permissive temperatures, though the decline in levels was not as great as that observed for PtdIns4P. This was not surprising as a similar result was reported when labelled phosphoinositides were assessed in $s t 4^{t s}$ cells, namely a decline in levels of $\operatorname{PtdIns}(4,5) P_{2}$ that was not as great as the decline in PtdIns4P levels [14].

At the permissive temperature, levels of PtdIns $3 \quad P$ were significantly lower in the ypp 1$41^{t s}$ mutant when compared to the wild-type; though levels of this phosphoinositide declined to similar levels in wild-type and mutant, following heat shock (Fig. 5B).

\section{Deletion of $S A C 1$ restores viability of $y p p 1^{t s}$ mutants under non-permissive conditions.}

PtdIns $4 P$ is essential for cell viability, but an upshift in temperature leads to a decrease in its synthesis (Fig 5B). If the lower level of PtdIns $4 P$ synthesized at $25^{\circ} \mathrm{C}$ in $y p p 1^{t s}$ mutants is the principal cause of lethality on temperature up shift, then limiting the activity of phosphatases that hydrolyse PtdIns $4 P$ should raise PtdIns $4 P$ levels of this phosphoinositide, thereby restoring viability. The only lipid phosphatases with enzymatic action towards PtdIns $4 P$ are those containing the Sac1 homology domain. There are five members of this family in yeast, Sac1, Fig4 and the three synaptojanin-like phosphatases Sj11/Inp51, Sj12/Inp52 and Sj13/Inp53 [17, 36]. Of these, Sac1 is the predominant 4-phosphatase in yeast, as cells lacking the corresponding gene have up to 12 times more PtdIns $4 P$ than wild-type cells [17, 37, 38]. Moreover, Stt4 (rather than Pik1 or Lsb6) synthesizes the majority of PtdIns $4 P$ that accumulates in $s a c 1 \Delta$ cells [35, 37]. Loss of Sac1 activity restored viability at $37^{0} \mathrm{C}$ to all three $y p p I^{\text {ts }}$ mutants tested (Fig. 6), further confirming that the essential function of Ypp1 is to facilitate PtdIns $4 P$ synthesis via activation of Stt4. 


\section{The MAPK cell wall integrity pathway operates normally in the $y p p 1-35^{t s}$ mutant.}

Sequential action by Stt4 and Mss4 generates PtdIns $(4,5) P_{2}$ which tethers the guanine nucleotide exchange factor Rom2 to the plasma membrane, via interaction with the Rom2 PH domain. This activates Rho1, which in turn activates Pkc1, initiating a phosphorylation cascade leading to activation of the MAPK Slt2 (reviewed in [39]). Compromising the function of Stt4 causes a decrease in the level of PtdIns4P and in turn, causes destabilization of the cell wall [14]. The same is true when function of Ypp1 is compromised (Fig. 5B and Fig. 1B), so one possibility is that these mutants fail to activate the cell wall integrity MAPK pathway. We investigated whether this was the case. As expected, Slt2 in wild-type cells is unphosphorylated at $25^{\circ} \mathrm{C}$, but is phosphorylated in the presence of caffeine, which is known to de-stabilize the cell wall (Fig 7A). Of the three mutants tested, ypp $1-35^{t s}$ was selected for investigating the activity of components involved in the cell wall integrity pathway, because this mutant was the most sensitive to caffeine (Fig. 1B). Slt2 was phosphorylated normally in response to caffeine in $y p p 1-35^{t s}$ (Fig. 7A). Phosphorylated Slt2 activates Rlm1, the major transactivator of genes involved in cell wall maintenance [39]. However, a cell wall integrity defect may still result if there is a defect downstream of Slt2, even though signalling through the MAPK cascade itself appears to be normal in ypp 1-35 ${ }^{t s}$ shifted to the non-permissive temperature. Given that there are mutants which are defective in Rlm1-mediated transcription, even when Slt2 is activated normally [40], we decided to measure transcription of a $L a c Z$ reporter controlled by the Rlm1-dependent promoter of $Y I L 117 \mathrm{c}$. In the presence of caffeine, Rlm1-mediated transcription was stimulated to the same extent in wild-type and ypp 1-35 $5^{t s}$ cells (Fig. 7B). Consequently, the cell wall integrity defect in $y p p 1-35^{t s}$ is not due to defective signaling downstream of Pkc1. Moreover, overexpression of components of this cascade including the MAPK kinase kinase Bck1, either of the redundant MAPK kinases (Mpk1/2), the MAPK Slt2, as well as Pkc1 itself, all failed to rescue the nogrowth defect at $37^{\circ} \mathrm{C}$ of the three ypp $1^{t s}$ mutants (not shown).

\section{Endocytosis of plasma membrane proteins is unaffected in the $y p p 1-35^{t s}$ mutant.}

Recently, it has been shown that overexpression of YPP1 suppresses the toxicity of the human A30P $\alpha$-synuclein $(\alpha$-syn) mutant that is associated with early onset Parkinson's disease. Elevated levels of Ypp1 lead to endocytosis and degradation of A30P $\alpha$-syn in the yeast vacuole [21]. However, $\alpha$-syn is found in the cytosol and is not native to yeast, and as such it is not a typical substrate for the endocytic process. We assessed the possible role Ypp1 might play in endocytosis by following the localization of yeast protein substrates that use the endocytic route for their delivery to the vacuole.

To examine the role of Ypp1 in endocytosis we followed the trafficking of the uridine permease Fuil. The rate of constitutive endocytosis of this transporter is relatively low, which permits visualization of this protein at the plasma membrane (unlike the a factor receptor, Ste3, for example, which undergoes rapid constitutive internalization). However, the rates of endocytosis and subsequent degradation of Fuil in the vacuole, are increased significantly in the presence of uridine [34]. We followed the intracellular trafficking of an Fuil-GFP fusion, synthesis of which was under the control of the inducible GAL10 promoter [34]. Cells were grown to exponential phase in galactose to induce synthesis of Fuil-GFP, followed by addition of glucose (to block permease synthesis) and a temperature shift to $37^{\circ} \mathrm{C}$. Cells were maintained at this temperature for 30 minutes to induce the temperature sensitive phenotype. At this stage, similar levels of Fuil-GFP were seen at the plasma membrane, in both wild-type and ypp 1-35 $5^{t s}$ mutant cells (Fig. 8). Also, vaculolar fluorescence was clearly observed because of the relative resistance of GFP to vacuolar hydrolases [34]. Uridine was then added to the cells, and the temperature was maintained at $37^{\circ} \mathrm{C}$. As can be seen in Fig. 8, Fuil-GFP staining is lost from the cell surfaces of both wild-type and ypp $1-35^{t s}$ cells after incubation for 15 or 60 minutes with 
uridine. Therefore, the ypp1-35 $5^{t s}$ mutation has no dramatic affect on the overall endocytosis rate of Fuil-GFP. To confirm that we were following an endocytic process we assessed the localization of the Fuil-GFP fusion in end $3 \Delta$ cells treated in the same way. End3 is essential for the internalization step of endocytosis [32]. As expected, the Fuil-GFP in the end $3 \Delta$ background was not internalized, remaining at the plasma membrane (Fig. 8). Additionally we saw similar results when we followed another endocytic cargo, Ste3-GFP in wild-type and ypp 1-35 $5^{\text {ts }}$ cells (not shown), so our data would suggest that low PtdIns $4 P$ does not inhibit endocytosis.

In the wild-type and ypp 1-35 cells, we noted that levels of internalized Fuil-GFP after the 30 minute heat shock, but prior to addition of uridine, were particularly high (Fig. 8). This was expected, because heat shock decreases the half-life of membrane transporters through stimulation of endocytosis [41, 42].

As well as stimulating endocytosis of Fuil, uridine also stimulates exocytic trafficking of this permease by inducing direct traffic from the Golgi to the endosomal system, bypassing the plasma membrane. This type of traffic, however, did not contribute to the changes in localization of Fuil-GFP we observed, because we repressed Fuil-GFP synthesis by addition of glucose, prior to heat shock and subsequent addition of uridine. Therefore, any changes in localization of FuilGFP caused by heat shock or uridine are only attributable to endocytic trafficking. This is confirmed by the lack of vacuolar staining in the end $3 \Delta$ background, which is blocked for the early stages of endocytosis, but not deficient in exocytic traffic [34].

The induction of endocytosis by heat shock meant that subtle changes caused by compromised Ypp1 function may not be observed at $37^{\circ} \mathrm{C}$. For this reason, we assessed localization of Fuil-GFP at $25^{\circ} \mathrm{C}$. As expected, the rate of endocytosis in response to addition of uridine was much slower at $25^{\circ} \mathrm{C}$ than at $37^{\circ} \mathrm{C}$. In wild-type cells, there was little change in levels of plasma membrane-associated Fui-GFP by fifteen minutes after addition of uridine (Fig. 9), in contrast to a complete lack of plasma membrane-associated transporter at the same stage at $37^{\circ} \mathrm{C}$ (Fig. 8). At $25^{\circ} \mathrm{C}$, by sixty minutes after addition of uridine, all of the Fuil-GFP had been internalized. However, there was no difference in Fuil-GFP internalization between the wild-type and $y p p 1-35^{t s}$ (Fig. 9). Even though $25^{\circ} \mathrm{C}$ is a permissive temperature for $y p p 1^{t s}$ mutants, the levels of PtdIns(4) $P$ are significantly lower in these mutants in comparison to levels in wild-type cells (Fig. 5B). On the other hand, it has been reported that elevated levels of PtdIns(4) $P$ which are found in sacl $\Delta$ cells, lead to impaired rates of endocytosis [35].This was true for endocytosis of Fuil-GFP, with plasma-membrane associated transporter clearly visible in sacl $1 \Delta$ cells even after sixty minutes of exposure to uridine, in contrast to the complete internalization of the transporter in wild-type cells (Fig. 9). Combining the sac1 $\Delta$ with ypp $1-35^{t s}$ recapitulated the wildtype kinetics of Fuil-GFP internalization (Fig. 9), which is consistent with our data showing the opposing effects of sacl $\triangle$ and $y p p 1-35^{t s}$ on PtdIns(4)P levels. In agreement with this is the compensation of the endocytic defect in sacl $\Delta$ cells in a background that is compromised for function of the PtdIns 4-kinase encoded by STT4 [35]. Not surprisingly, levels of PtdIns(4)P are restored to near wild-type levels in an $s t 4^{t s}{ }^{t s} s 1^{t s}$ double mutant [37].

\section{DISCUSSION}

\section{Biological interaction between Stt4 and Ypp1.}

A PSI-blast search revealed six putative orthologues of Ypp1 in humans; with one of them, TTC7B (Q86TV6), sharing 15\% amino acid sequence identity with Ypp1 [21]. Use of algorithms such as Prosite and Pfam, does not identify any recognizable domains in Ypp1. However, use of a recently developed search tool [43] identifies two putative tetratricopeptide repeat (TPR) protein-protein interaction domains, one towards the $\mathrm{N}$ terminus and the other 
towards the $\mathrm{C}$ terminus. We characterized the role played by Ypp1 in cell physiology by generating conditional lethal alleles of the corresponding gene.

A Tandem Affinity purification (TAP) tag screen revealed a physical interaction between the PtdIns 4-kinase Stt4 and Ypp1 [20], which we confirmed using a two-hybrid assay. Stt4 is found at the plasma membrane [14]. Ypp1 localises nearby, in a punctate pattern around the periphery of the cell $[21,44]$. Until now, there have been no reports describing a functional interaction between these proteins. Our study is the first to demonstrate a functional interaction between the PtdIns 4-kinase Stt4 and Ypp1. We show the phenotypes of stt $4^{t s}$ mutants are similar to those of our $y p p I^{t s}$ mutants, namely a reversal of the temperature sensitivity by osmotic stabilization of media, sensitivity to agents that destabilize the cell wall, such as caffeine (also rescued by osmotic stabilization), and defects in actin organization. In addition we show that overexpression of Stt4 suppressess the growth defect of two ypp $1^{t s}$ mutants. Overexpression of the other PtdIns 4-kinases in yeast, Pik1 and Lsb6, does not suppress the temperature sensitive growth defect of $y p p 1^{t s}$ mutants at $37^{0} \mathrm{C}$. This implies a specific role for Ypp1 in Stt4-dependant events at the plasma membrane, as opposed to a general role connected with the function of all three PtdIns 4-kinases in S.cerevisiae. In agreement with this, we see reduced binding at the cell periphery by a GFP-PH ${ }^{\mathrm{Osh} 2}$ sensor which is specific for PtdIns $4 P$ and $\operatorname{PtdIns}(4,5) P_{2}$. This is more evident in the ypp $1-35^{t s}$ mutant, which shows clear reduction of staining even at the permissive as well as the non-permissive temperature. Staining at the plasma membrane by this sensor is directly related to Stt4 activity, as plasma membrane localization of GFP-PH ${ }^{\mathrm{Osh} 2}$ is lost in an $s t t 4^{t s}$ mutant shifted to the non-permisive temperature [33]. The clear decrease in PH domain staining at the cell membrane in $y p p 1^{t s}$ mutants is accompanied by an increase in the intensity of punctate intracellular staining, especially in the ypp $1-35^{t s}$ mutant at $25^{\circ} \mathrm{C}$ and the $y p p 1-41^{t s}$ mutant at $37^{\circ} \mathrm{C}$. In addition, this intracellular punctate staining is entirely due to PtdIns $4 P$ generated by Pik1, as GFP-PH ${ }^{\text {Osh2 } 2}$ staining is lost completely when Pik1 activity is depleted, but retained when Stt4 is inactivated [33]. The increase in intensity of punctate intracellular staining in the ypp $1-35^{t s}$ mutant at $25^{\circ} \mathrm{C}$ and the $y p p 1-41^{t s}$ mutant at $37^{\circ} \mathrm{C}$ could be due to a compensatory increase of PtdIns $4 P$ by Pik1. Alternatively, levels of the $\mathrm{PH}$ sensor may not be saturating, so a decrease in plasma membrane associated 4-phosphorylated PtdIns means that more sensor is free to bind this lipid at intracellular locations.

Audhya et al. report an increase in the levels of PtdIns $4 P$ in wild-type cells, following a 1 hour upshift to $37^{\circ} \mathrm{C}$ [9]. This is contrary to our observation of heat shock leading to a reduction in levels of this phosphoinositide. The difference may be due to the method used for radiolabelling phosphoinositides. Audhya et al. labelled cells by incubation with $\left[{ }^{3} \mathrm{H}\right]$ inositol for 10 minutes [9], so measurable levels of phosphoinositides could be influenced by differences in the rate of incorporation of label. We labelled to near-steady state equilibrium so any changes seen in phosphoinositide levels relate solely to their mass.

Consequently, our results are in agreement with another study which also used equilibrium labelling [16]. In any case, our data thus far suggest the primary defect responsible for phenotypes exhibited by ypp $I^{t s}$ mutants is a reduction in levels of PtdIns $4 P$. This was confirmed by loss of the Sac1 PtdIns 4-phosphatase restoring growth to all three $y p p I^{\text {ts }}$ mutants at $37^{0} \mathrm{C}$.

\section{The Pkc1-dependent MAPK cascade is not defective in the $y p p 1-35^{t s}$ mutant.}

Optimal activity of Stt4 is needed for cell wall integrity. The PtdIns $(4,5) P_{2}$, synthesized at the plasma membrane by sequential action of Stt4 and Mss4, is bound by the PH domain of Rom2, which in turn localizes Rom2 to the plasma membrane where it activates Rho1. This leads to activation of the Rho1/Pkc1-mediated MAPK cascade. Inactivation of Stt4 leads to mislocalization of Rom2, and the activation of the cascade is severely compromised, leading to 
limited phosphorylation of the Slt2 MAP kinase [14]. The ypp $1^{t s}$ mutants were sensitive to agents that destabilize the cell wall, so we anticipated that activation of Slt2 and subsequent activation of the Rlm1 transcription factor would also be abrogated in these strains, but this was not the case. In ypp 1-35 $5^{\text {ts }}$, Slt2 is phosphorylated and Rlm1 mediated transcription is stimulated in response to an external stimulus known to activate the cell wall integrity MAPK cascade, namely incubation with caffeine. Accordingly, though the level of plasma membrane associated PtdIns $4 P$ in $y p p 1$ $35^{t s}$ may be low (Fig. 5A), it is sufficient to allow adequate $\operatorname{PtdIns}(4,5) P_{2}$ synthesis for proper activation of the cell-wall integrity cascade.

\section{Compromise of Ypp1 function does not lead to a defect in internalization of endocytic cargo proteins.}

Phosphoinoisitides play key roles in endosomal trafficking. For example, the 3phosphorylated derivatives of PtdIns play roles throughout the endocytic pathway (reviewed in [1]). In addition, a number of recent studies have indicated that 4-phosphorylated derivatives of PtdIns are also required for endocytosis. Defects in the endocytic pathway occur in the sac1 $\Delta$ background, in which levels of PtdIns4P are elevated by up to 10 fold [35]. However, we show that the drop in PtdIns $4 P$ observed in the $y p p^{t s}$ mutants does not affect internalization of Fuil and Ste3, two well-established transmembrane substrates of the endocytic machinery. This suggests that intracellular levels of PtdIns $4 P$ can fall significantly, without a major effect on endocytosis. In agreement with this are data from a similar approach using cells compromised for function of the Stt4 PtdIns 4-kinase itself. When incubated at non-permissive temperature, Ste6 (a plasma membrane transporter subjected to constitutive endocytosis), is efficiently internalized and targeted to the vacuole in both $s t 4^{t s}$ and wild-type cells [9]. Given that endocytosis is particularly sensitive to elevated PtdIns $4 P$, it follows that that the defect in endocytosis we observed in sac1 $\Delta$ cells was rescued by combination with a $y p p 1^{t s}$ mutation that restores cellular levels of this phosphoinositide.

Some components of the clathrin mediated endocytic machinery are PtdIns $(4,5) P_{2^{-}}$ binding proteins $[45,46]$. Furthermore, $\operatorname{Ptd} \operatorname{Ins}(4,5) P_{2}$ is also involved in re-modelling of the actin cytoskeleton, which in turn facilitates endocytosis $[47,48]$. PtdIns $(4,5) P_{2}$ is synthesized by Mss4, the only PtdIns 4-phosphate 5-kinase in yeast. As expected, a reduction in levels of $\operatorname{PtdIns}(4,5) P_{2}$ caused by loss of Mss4 function, leads to a defect in endocytosis [49]. Levels of PtdIns4P, the precursor of PtdIns $(4,5) P_{2}$ synthesis, fall in the $y p p I^{t s}$ mutants. However, this is not accompanied by a significant fall in PtdIns $(4,5) P_{2}$ synthesis. This may explain why endocytosis of Fui-GFP remained unaffected, given that activity of the $\operatorname{PtdIns}(4,5) P_{2}$ effectors involved in endocytosis do not change significantly.

Expression of the Parkinson's disease A30P $\alpha$-syn mutant is lethal in yeast. This is suppressed by raising the levels of Ypp1, which elevates endocytosis and degradation of A30P $\alpha$ syn [21]. However, this may not be due to a stimulation of endocytosis itself. Instead, the enhanced rate of $\mathrm{A} 30 \mathrm{P} \alpha$-syn degradation may be due to recruitment of A30P $\alpha$-syn to the plasma membrane, where it becomes assimilated into the naturally occurring endocytic processes operating in yeast. Three observations are in agreement with this. Firstly, Ypp1 is localized in a punctate pattern in close proximity to the plasma membrane. Secondly, Ypp1 binds to A30P $\alpha-$ syn but not to the wild-type or A53T $\alpha$-syn mutant. This explains why A30P $\alpha$-syn is degraded, while wild-type or A53T $\alpha$-syn remain intact [21]. Thirdly, loss of Ypp1 function does not affect the endocytosis of yeast membrane proteins that are endocytic substrates (Figs. 8 and 9).

We investigated the phenotypes displayed by three ypp $1^{t s}$ alleles. Multiple amino acid substitutions were found in the corresponding mutant proteins, with seven substitutions found in ypp $1-35^{\text {ts }}$ and ypp $1-41^{\text {ts }}$ and six substitutions in ypp $1-39^{\text {ts }}$. Further work will be required to 
determine which mutations are responsible for the $t s$ phenotypes. We have shown that Ypp1 contributes to generation of PtdIns $4 P$ by the lipid kinase Stt4. Some of the mutations fall within the putative TPR protein-protein interaction domains of Ypp1, which may explain the loss of interaction with the Stt4 lipid kinase. The precise role played by Ypp1 in function of Stt4 remains to be determined, and may involve delivery of PtdIns substrate to Stt4, or a direct effect on the catalytic action of Stt4 mediated by interaction with Ypp1.

\section{ACKNOWLEDGEMENTS}

This work was supported by grant BB/E020550/1 from the Biotechnology and Biological Research Council (BBSRC) to B.P. C.Z. was a recipient of a scholarship from the KC Wong Foundation and the China Scholarship Council. We thank Tim Levine (Institute of Opthalmology, University College London) for providing the pTL511 vector, Rob Piper (Department of Physiology and Biophysics, University of Iowa) for providing the pJLU34 vector, and Rosine Haguenauer-Tsapis for providing the pFL38GalFUI1-GFP vector (Institut Jacob Monod, Paris).

1 Strahl, T. and Thorner, J. (2007) Synthesis and function of membrane phosphoinositides in budding yeast, Saccharomyces cerevisiae. Biochim. Biophys. Acta. 1771, 353-404

2 Flanagan, C. A., Schnieders, E. A., Emerick, A. W., Kunisawa, R., Admon, A. and Thorner, J. (1993) Phosphatidylinositol 4-kinase: gene structure and requirement for yeast cell viability. Science. 262, 1444-1448

3 Garcia-Bustos, J. F., Marini, F., Stevenson, I., Frei, C. and Hall, M. N. (1994) PIK1, an essential phosphatidylinositol 4-kinase associated with the yeast nucleus. Embo J. 13, 2352-2361

4 Yoshida, S., Ohya, Y., Goebl, M., Nakano, A. and Anraku, Y. (1994) A novel gene, STT4, encodes a phosphatidylinositol 4-kinase in the PKC1 protein kinase pathway of Saccharomyces cerevisiae. J. Biol. Chem. 269, 1166-1172

5 Barylko, B., Gerber, S. H., Binns, D. D., Grichine, N., Khvotchev, M., Sudhof, T. C. and Albanesi, J. P. (2001) A novel family of phosphatidylinositol 4-kinases conserved from yeast to humans. J. Biol. Chem. 276, 7705-7708

6 Han, G. S., Audhya, A., Markley, D. J., Emr, S. D. and Carman, G. M. (2002) The Saccharomyces cerevisiae LSB6 gene encodes phosphatidylinositol 4-kinase activity. J. Biol. Chem. 277, 47709-47718

7 Shelton, S. N., Barylko, B., Binns, D. D., Horazdovsky, B. F., Albanesi, J. P. and Goodman, J. M. (2003) Saccharomyces cerevisiae contains a Type II phosphoinositide 4kinase. Biochem. J. 371, 533-540

8 Cutler, N. S., Heitman, J. and Cardenas, M. E. (1997) STT4 is an essential phosphatidylinositol 4-kinase that is a target of wortmannin in Saccharomyces cerevisiae. J. Biol. Chem. 272, 27671-27677

9 Audhya, A., Foti, M. and Emr, S. D. (2000) Distinct roles for the yeast phosphatidylinositol 4-kinases, Stt4p and Pik1p, in secretion, cell growth, and organelle membrane dynamics. Mol. Biol. Cell. 11, 2673-2689

10 Chang, F. S., Han, G. S., Carman, G. M. and Blumer, K. J. (2005) A WASp-binding type Il phosphatidylinositol 4-kinase required for actin polymerization-driven endosome motility. J. Cell Biol. 171, 133-142 
Hama, H., Schnieders, E. A., Thorner, J., Takemoto, J. Y. and DeWald, D. B. (1999) Direct involvement of phosphatidylinositol 4-phosphate in secretion in the yeast Saccharomyces cerevisiae. J. Biol. Chem. 274, 34294-34300 Walch-Solimena, C. and Novick, P. (1999) The yeast phosphatidylinositol-4-OH kinase Pik1 regulates secretion at the Golgi. Nat. Cell Biol. 1, 523-525 Strahl, T., Hama, H., DeWald, D. B. and Thorner, J. (2005) Yeast phosphatidylinositol 4kinase, Pik1, has essential roles at the Golgi and in the nucleus. J. Cell Biol. 171, 967-979 Audhya, A. and Emr, S. D. (2002) Stt4 PI 4-kinase localizes to the plasma membrane and functions in the Pkc1-mediated MAP kinase cascade. Dev. Cell. 2, 593-605 Trotter, P. J., Wu, W. I., Pedretti, J., Yates, R. and Voelker, D. R. (1998) A genetic screen for aminophospholipid transport mutants identifies the phosphatidylinositol 4kinase, Stt4p, as an essential component in phosphatidylserine metabolism. J. Biol. Chem. 273, 13189-13196

16 Desrivieres, S., Cooke, F. T., Parker, P. J. and Hall, M. N. (1998) MSS4, a phosphatidylinositol-4-phosphate 5-kinase required for organization of the actin cytoskeleton in Saccharomyces cerevisiae. J. Biol. Chem. 273, 15787-15793 Guo, S., Stolz, L. E., Lemrow, S. M. and York, J. D. (1999) SAC1-like domains of yeast SAC1, INP52, and INP53 and of human synaptojanin encode polyphosphoinositide phosphatases. J. Biol. Chem. 274, 12990-12995 Hendricks, K. B., Wang, B. Q., Schnieders, E. A. and Thorner, J. (1999) Yeast homologue of neuronal frequenin is a regulator of phosphatidylinositol-4-OH kinase. Nat. Cell Biol. 1, 234-241

19 Stack, J. H., DeWald, D. B., Takegawa, K. and Emr, S. D. (1995) Vesicle-mediated protein transport: regulatory interactions between the Vps15 protein kinase and the Vps34 PtdIns 3-kinase essential for protein sorting to the vacuole in yeast. J. Cell Biol. 129, 321-334

20 Hazbun, T. R., Malmstrom, L., Anderson, S., Graczyk, B. J., Fox, B., Riffle, M., Sundin, B. A., Aranda, J. D., McDonald, W. H., Chiu, C. H., Snydsman, B. E., Bradley, P., Muller, E. G., Fields, S., Baker, D., Yates, J. R., 3rd and Davis, T. N. (2003) Assigning function to yeast proteins by integration of technologies. Mol. Cell. 12, 1353-1365 Flower, T. R., Clark-Dixon, C., Metoyer, C., Yang, H., Shi, R., Zhang, Z. and Witt, S. N. (2007) YGR198w (YPP1) targets A30P alpha-synuclein to the vacuole for degradation. J. Cell Biol. 177, 1091-1104

Rose, M. D., Winston, F. and Hieter, P. (1990) Methods in Yeast Genetics: A Cold Spring Harbor Laboratory Course Manual, Cold Spring Harbor Laboratory Press, New York

Goldstein, A. L. and McCusker, J. H. (1999) Three new dominant drug resistance cassettes for gene disruption in Saccharomyces cerevisiae. Yeast. 15, 1541-1553

24 Wach, A., Brachat, A., Rebischung, C., Steiner, S., Pokorni, K., Heesen, S. and Philippsen, P. (1998) in Yeast Gene Analysis, vol. 26 (Brown, A. J. P. and Tuite, M. F., eds.), pp. 67-81, Academic Press, London Fenton, C., Xu, H., Petersen, E. I., Petersen, S. B. and El-Geweley, M. R. (2002), vol. 182 (Braman, J., ed.), pp. 231-241, Humana Press, Totowa Hu, B., Liao, C., Millson, S. H., Mollapour, M., Prodromou, C., Pearl, L. H., Piper, P. W. and Panaretou, B. (2005) Qri2/Nse4, a component of the essential Smc5/6 DNA repair complex. Mol. Microbiol. 55, 1735-1750

27 Mollapour, M., Phelan, J. P., Millson, S. H., Piper, P. W. and Cooke, F. T. (2006) Weak acid and alkali stress regulate phosphatidylinositol bisphosphate synthesis in Saccharomyces cerevisiae. Biochem. J. 395, 73-80 
Gietz, R. D. and Sugino, A. (1988) New yeast-Escherichia coli shuttle vectors constructed with in vitro mutagenized yeast genes lacking six-base pair restriction sites. Gene. 74, 527-534 James, P., Halladay, J. and Craig, E. A. (1996) Genomic libraries and a host strain designed for highly efficient two-hybrid selection in yeast. Genetics. 144, 1425-1436 Panaretou, B., Prodromou, C., Roe, S. M., O'Brien, R., Ladbury, J. E., Piper, P. W. and Pearl, L. H. (1998) ATP binding and hydrolysis are essential to the function of the Hsp90 molecular chaperone in vivo. Embo J. 17, 4829-4836 Jung, U. S., Sobering, A. K., Romeo, M. J. and Levin, D. E. (2002) Regulation of the yeast $\mathrm{R} \operatorname{lm} 1$ transcription factor by the Mpk1 cell wall integrity MAP kinase. Mol. Microbiol. 46, 781-789

Benedetti, H., Raths, S., Crausaz, F. and Riezman, H. (1994) The END3 gene encodes a protein that is required for the internalization step of endocytosis and for actin cytoskeleton organization in yeast. Mol. Biol Cell. 5, 1023-1037

Roy, A. and Levine, T. P. (2004) Multiple pools of phosphatidylinositol 4-phosphate detected using the pleckstrin homology domain of Osh2p. J. Biol. Chem. 279, 4468344689

Blondel, M. O., Morvan, J., Dupre, S., Urban-Grimal, D., Haguenauer-Tsapis, R. and Volland, C. (2004) Direct sorting of the yeast uracil permease to the endosomal system is controlled by uracil binding and Rsp5p-dependent ubiquitylation. Mol. Biol. Cell. 15, 883-895

Tahirovic, S., Schorr, M. and Mayinger, P. (2005) Regulation of intracellular phosphatidylinositol-4-phosphate by the Sac1 lipid phosphatase. Traffic. 6, 116-130 Hughes, W. E., Cooke, F. T. and Parker, P. J. (2000) Sac phosphatase domain proteins. Biochem. J. 350, 337-352

37 Foti, M., Audhya, A. and Emr, S. D. (2001) Sac1 lipid phosphatase and Stt4 phosphatidylinositol 4-kinase regulate a pool of phosphatidylinositol 4-phosphate that functions in the control of the actin cytoskeleton and vacuole morphology. Mol. Biol. Cell. 12, 2396-2411

38 Konrad, G., Schlecker, T., Faulhammer, F. and Mayinger, P. (2002) Retention of the yeast Sac1p phosphatase in the endoplasmic reticulum causes distinct changes in cellular phosphoinositide levels and stimulates microsomal ATP transport. J. Biol. Chem. 277, 10547-10554

39 Levin, D. E. (2005) Cell wall integrity signaling in Saccharomyces cerevisiae. Microbiol Mol. Biol. Rev. 69, 262-291

40 Truman, A. W., Millson, S. H., Nuttall, J. M., Mollapour, M., Prodromou, C. and Piper, P. W. (2007) In the yeast heat shock response, Hsfl-directed induction of Hsp90 facilitates the activation of the Slt2 (Mpk1) mitogen-activated protein kinase required for cell integrity. Eukaryot. Cell. 6, 744-752

41 Volland, C., Urban-Grimal, D., Geraud, G. and Haguenauer-Tsapis, R. (1994) Endocytosis and degradation of the yeast uracil permease under adverse conditions. J. Biol. Chem. 269, 9833-9841

42 Bultynck, G., Heath, V. L., Majeed, A. P., Galan, J. M., Haguenauer-Tsapis, R. and Cyert, M. S. (2006) Slm1 and $\operatorname{sim} 2$ are novel substrates of the calcineurin phosphatase required for heat stress-induced endocytosis of the yeast uracil permease. Mol. Cell Biol. 26, 4729-4745

43 Karpenahalli, M. R., Lupas, A. N. and Soding, J. (2007) TPRpred: a tool for prediction of TPR-, PPR- and SEL1-like repeats from protein sequences. BMC Bioinformatics. 8, 2 Huh, W. K., Falvo, J. V., Gerke, L. C., Carroll, A. S., Howson, R. W., Weissman, J. S. and O'Shea, E. K. (2003) Global analysis of protein localization in budding yeast. Nature. 425, 686-691 
45 D'Hondt, K., Heese-Peck, A. and Riezman, H. (2000) Protein and lipid requirements for endocytosis. Annu. Rev. Genet. 34, 255-295

46 Jost, M., Simpson, F., Kavran, J. M., Lemmon, M. A. and Schmid, S. L. (1998)

Phosphatidylinositol-4,5-bisphosphate is required for endocytic coated vesicle formation. Curr. Biol. 8, 1399-1402

47 Perrais, D. and Merrifield, C. J. (2005) Dynamics of endocytic vesicle creation. Dev. Cell. 9, 581-592

48 Kaksonen, M., Toret, C. P. and Drubin, D. G. (2006) Harnessing actin dynamics for clathrin-mediated endocytosis. Nat. Rev. Mol. Cell Biol. 7, 404-414

49 Desrivieres, S., Cooke, F. T., Morales-Johansson, H., Parker, P. J. and Hall, M. N. (2002) Calmodulin controls organization of the actin cytoskeleton via regulation of phosphatidylinositol (4,5)-bisphosphate synthesis in Saccharomyces cerevisiae. Biochem. J. 366, 945-951 
Table 1. The yeast strains used in this study

\begin{tabular}{|c|c|c|}
\hline \multicolumn{2}{|c|}{ 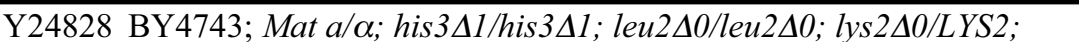 } & \multirow[t]{2}{*}{$\overline{\text { EUROSCARF* }}$} \\
\hline & 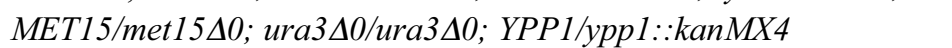 & \\
\hline $\mathrm{ZC0}$ & $\begin{array}{l}M A T a, \text { leu } 2 \Delta 0, \text { ura3 } \Delta 0, \text { his } 3 \Delta 1 \text {, lys } 2 \Delta 0, \text { MET15, ypp } 1: \because \text { kanMX } 4 \text {, } \\
\text { bearing pYC3P (YPP1/URA3) }\end{array}$ & this study \\
\hline $\mathrm{ZC1}$ & $\begin{array}{l}M A T a \text {, leu2 } \Delta 0 \text {, ura3 } \Delta 0 \text {, his } 3 \Delta 1 \text {, lys } 2 \Delta 0, \text { MET15, ypp } 1: \because \text { kanMX } 4 \text {, } \\
\text { bearing pYC1P (YPP1/LEU2) }\end{array}$ & this study \\
\hline $\mathrm{ZC} 2$ & $\begin{array}{l}M A T a \text {, leu2 } \Delta 0 \text {, ura3 } \Delta 0, \text { his } 3 \Delta 1 \text {, lys } 2 \Delta 0, \text { MET15, ypp } 1:: \text { kanMX } 4 \text {, } \\
\left.\text { bearing pYC1P2 (ypp } 1-2^{t s} / L E U 2\right)\end{array}$ & \\
\hline $\mathrm{ZC} 3$ & $\begin{array}{l}M A T a \text {, leu2 } \Delta 0 \text {, ura3 } \Delta 0 \text {, his } 3 \Delta 1 \text {, lys } 2 \Delta 0, \text { MET15, ypp } 1: \because \text { kanMX } 4 \text {, } \\
\left.\text { bearing pYC1P6 (ypp } 1-6^{t s} / L E U 2\right)\end{array}$ & study \\
\hline $\mathrm{ZC4}$ & $\begin{array}{l}\text { MAT a, leu } 2 \Delta 0 \text {, ura3 } \Delta 0 \text {, his } 3 \Delta 1 \text {, lys } 2 \Delta 0, \text { MET15, ypp } 1 \Delta:: \operatorname{kanMX} 4 \text {, } \\
\left.\text { bearing pYC1P30 (ypp } 1-30^{t s} / L E U 2\right)\end{array}$ & this study \\
\hline $\mathrm{ZC} 5$ & $\begin{array}{l}\text { MAT a, leu } 2 \Delta 0 \text {, ura3 } \Delta 0 \text {, his } 3 \Delta 1 \text {, lys } 2 \Delta 0, \text { MET15, yp } \\
\left.\text { bearing pYC1P34 (ypp } 1-34^{t s} / L E U 2\right)\end{array}$ & this study \\
\hline ZC6 & $\begin{array}{l}\text { MATa, leu2 } \Delta 0, \text { ura3 } \Delta 0, \text { his } 3 \Delta 1, \text { lys } 2 \Delta 0, \text { MET15, yppl } \\
\left.\text { bearing pYC1P35 (ypp } 1-35^{t s} / L E U 2\right)\end{array}$ & this study \\
\hline $\mathrm{ZC7}$ & $\begin{array}{l}\text { MATa, leu } 2 \Delta 0, \text { ura3 } \Delta 0 \text {, his } 3 \Delta 1 \text {, lys } 2 \Delta 0, \text { MET15, ypp } 1: \text { kan } M X 4 \text {, } \\
\left.\text { bearing pYC1P39 (ypp } 1-39^{t s} / L E U 2\right)\end{array}$ & this study \\
\hline $\mathrm{ZC} 8$ & $\begin{array}{l}\text { MAT a, leu } 2 \Delta 0 \text {, ura3 } \Delta 0 \text {, his } 3 \Delta 1 \text {, lys } 2 \Delta 0, \text { MET15, ypp } 1: \text { kanMX } 4 \text {, } \\
\left.\text { bearing pYC1P41 (ypp } 1-41^{t s} / L E U 2\right)\end{array}$ & this study \\
\hline $\mathrm{ZC} 21$ & ZC1 (YPP1), sac1 $\Delta:: h p h$ & this study \\
\hline $\mathrm{ZC} 22$ & ZC6 $\left(y p p 1-35^{t s}\right)$, sacl $\Delta:: h p h$ & this study \\
\hline $\mathrm{ZC} 23$ & ZC7 $\left(y p p 1-39^{t s}\right)$, sacl $\Delta:: h p h$ & this study \\
\hline $\mathrm{ZC} 24$ & ZC8 $\left(y p p 1-41^{t s}\right)$, sacl $1: \because h p h$ & this study \\
\hline Y12992 & 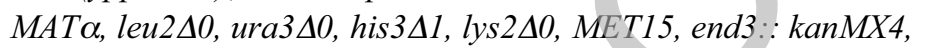 & EUROSCARF* \\
\hline PJ69-4a & 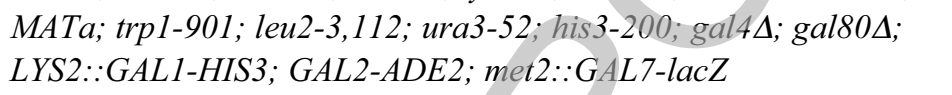 & $(29)$ \\
\hline PJ69-4 $\alpha$ & 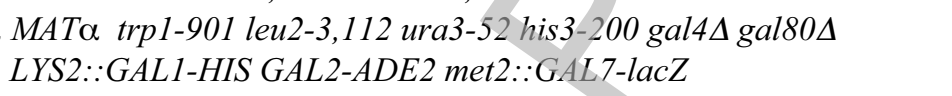 & $(29)$ \\
\hline
\end{tabular}

*EUROpean Saccharoymces Cerevisiae ARchive for Functional analysis 


\section{Figure legends}

Figure 1 The phenotypes displayed by conditional mutants of YPP1.

(A) Osmoremedial temperature sensitivity. YPP1 wild-type (ZC1) and conditional mutant strains (ZC2-8) were streaked on YPD plates with and without $1 \mathrm{M}$ sorbitol, and incubated for 3 days at $25^{\circ} \mathrm{C}$ or $37^{\circ} \mathrm{C}$. (B) The sensitivity of $\boldsymbol{y p p} \mathbf{1}^{\text {ts }}$ mutants to caffeine and SDS. $Y P P 1$ wildtype and $y p p 1^{t s}$ mutants were grown at $25^{\circ} \mathrm{C}$ to exponential phase, and diluted to equal cell density. Six-fold serial dilutions were spotted across YPD, or YPD containing the indicated concentrations of SDS, sorbitol, caffeine and caffeine plus sorbitol, followed by incubation at $30^{\circ} \mathrm{C}$ for 3 days.

Figure 2. Cells lacking Ypp1 activity fail to reorganize the actin cytoskeleton during heat shock.

YPP1 (ZC1) and ypp $1^{\text {ts }}$ mutants (ZC6 and 8) were grown to exponential phase at $25^{\circ} \mathrm{C}$ and then shifted to $37^{\circ} \mathrm{C}$ for 3 hours. Cells were fixed with formaldehyde. Actin cables and cortical actin patches were stained with rhodamine-phalloidin (A), corresponding phase images $(\mathrm{P})$ are also presented.

\section{Figure 3. STT4 is a multicopy suppressor of $y p p 1^{t s}$.}

The YPP1 wild-type and $y p p 1^{\text {ts }}$ mutants ( $\mathrm{ZCl}$ and $\left.\mathrm{ZC} 6-8\right)$ were transformed with multicopy vectors bearing the ORFs indicated in the central panel under the control of the MET25 promoter. Gene expression was induced by inoculating on selective media lacking methionine followed by incubation for 3 days at $25^{\circ} \mathrm{C}$ or $37^{\circ} \mathrm{C}$.

\section{Figure 4. Interaction with $\mathrm{Stt} 4$ is abrogated by $\mathrm{ypp}^{\mathrm{ts}}$ mutations.}

Two-hybrid interaction in diploid his 3-200/his3-200 auxotrophs expressing BD-Stt4 plus ADYpp1 or the indicated $\mathrm{AD}$-ypp $1^{\text {ts }}$ mutants. Cells were incubated at $25^{\circ} \mathrm{C}$ or $37^{\circ} \mathrm{C}$ on $\mathrm{SD}$ media lacking histidine. Interaction between $\mathrm{AD}$ - and $\mathrm{BD}$-fusions is scored by growth, as this leads to expression of a HIS3 reporter. All plates contained $1 \mathrm{mM} 3-\mathrm{AT}$, which inhibits basal activity of the HIS3 reporter product.

Figure 5 At restrictive temperature, $y p p 1^{t s}$ mutants display a diminished level of plasma membrane associated 4-phosphorylated PtdIns.

(A) Using a Pleckstrin homology (PH) domain sensor. $Y P P 1$ wild-type and $y p p I^{\text {ts }}$ mutants (ZC1, ZC6 and ZC8) were transformed with a vector bearing a tandemly repeated dimer of $\mathrm{PH}^{\mathrm{Osh} 2}$ bracketed by GFP. Strains were grown at $25^{\circ} \mathrm{C}$ to exponential phase. Prior to imaging, an aliquot of each culture was shifted to a strongly non-permissive temperature $\left(39^{\circ} \mathrm{C}\right)$ for 15 minutes. (B) $\left[{ }^{3} \mathbf{H}\right]$ inositol labelling. YPP1 wild-type (ZC1) and the ypp 1-4 $1^{\text {ts }}$ mutant (ZC8) were incubated with $\left[{ }^{3} \mathrm{H}\right]$ inositol at $25^{\circ} \mathrm{C}$ to label all inositol-based lipids to near steady-state equilibrium. Subsequently, cultures were split in two, with one aliquot maintained at $25^{\circ} \mathrm{C}$ and the other shifted to $37^{0} \mathrm{C}$ for 1 hour. $\left[{ }^{3} \mathrm{H}\right]$ inositol-containing lipids were extracted and deacylated. The glycerophosphoinositols were separated by HPLC and quantified by scintillation counting. All 
data were corrected to control $\left[{ }^{3} \mathrm{H}\right]$-PtdIns levels, which were, wild-type: 941,361 cpm and ypp1$41^{t s}: 1,011,448 \mathrm{cpm}$. Error bars represent \pm s.e.m. $(n=3)$.

Figure 6. Viability of $y p p 1^{t s}$ mutants at non-permissive conditions is restored in a sac14 background.

$Y P P 1$ wild-type (ZC1), ypp $1^{t s}$ mutants (ZC6-8) and corresponding isogenic sac1 4 strains (ZC2124) were grown at $25^{\circ} \mathrm{C}$ to exponential phase, and diluted to equal cell density. Six-fold serial dilutions were spotted across YPD followed by incubation for 3 days, at the temperatures indicated.

Figure 7. The MAP kinase cell wall integrity pathway is activated in the $y p p 1-35^{t s}$ mutant, in response to caffeine.

(A) YPP1 (ZC1) and the ypp 1-35 ts mutant (ZC6) were grown to exponential phase at $25^{\circ} \mathrm{C}$ and then incubated for 1 hour in the presence or absence of $10 \mathrm{mM}$ caffeine. Cells were harvested and levels of dually phosphorylated Slt2 (indicated as Slt2-P) and total Slt2, were detected on western blots using appropriate antisera. (B) The same strains were transformed with a vector bearing a YIL117c-promoter LacZ fusion. LacZ activity was assayed following 1 hour after the addition of $10 \mathrm{mM}$ caffeine. YIL117c-LacZ is a reporter for $\mathrm{R} \operatorname{lm} 1$ dependent transcription (data on $\mathrm{Y}$ axis are presented as LacZ Miller units, error bars represent \pm s.e.m. $(n=3)$.

\section{Figure 8. Endocytosis of Fuil-GFP promoted by uridine at $37^{0} \mathrm{C}$.}

Cells producing Fuil-GFP under control of the GAL10 promoter were grown at $25^{\circ} \mathrm{C}$ in standard defined media with galactose, to exponential phase. Glucose $(2 \%)$ was added to repress synthesis of the fusion, and cells were shifted to $37^{\circ} \mathrm{C}$. After 30 minutes at $37^{\circ} \mathrm{C}$, uridine was added to induce endocytosis. Cells were visualized prior to addition of uridine, and at the intervals indicated after addition of uridine. Identical fields are shown under fluorescence (Fuil-GFP) and DIC optics.

\section{Figure 9. Endocytosis of Fuil-GFP promoted by uridine at $25^{\circ} \mathrm{C}$.}

Cells producing Fuil-GFP under control of the GAL10 promoter were grown at $25^{\circ} \mathrm{C}$ in standard defined media with galactose to exponential phase. Glucose $(2 \%)$ was added to repress synthesis of the fusion. After 30 minutes at $25^{\circ} \mathrm{C}$, uridine was added to induce endocytosis. Cells were visualized prior to addition of uridine $(0 \mathrm{~min})$, and at the intervals indicated after addition of uridine. Identical fields are shown under fluorescence (Fuil-GFP) and DIC optics. 


\section{Figure 1}

A.

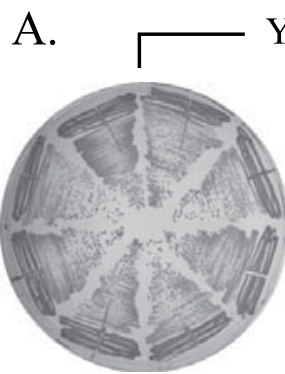

$25^{\circ} \mathrm{C}$
YPD

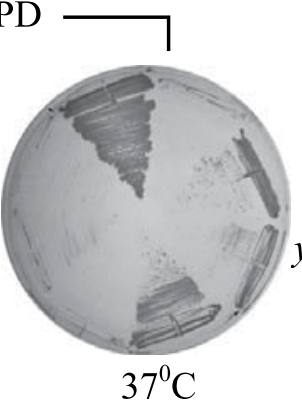

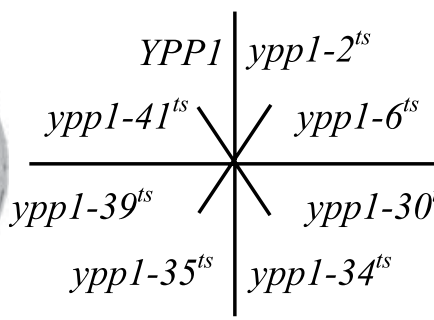

$y p p 1-35^{t s} \mid y p p 1-34^{t s}$

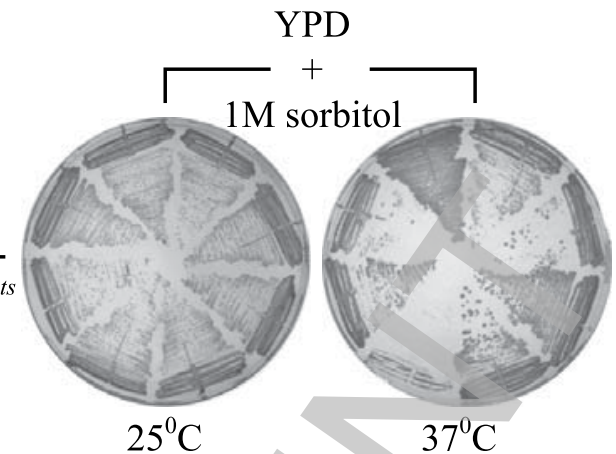

B.

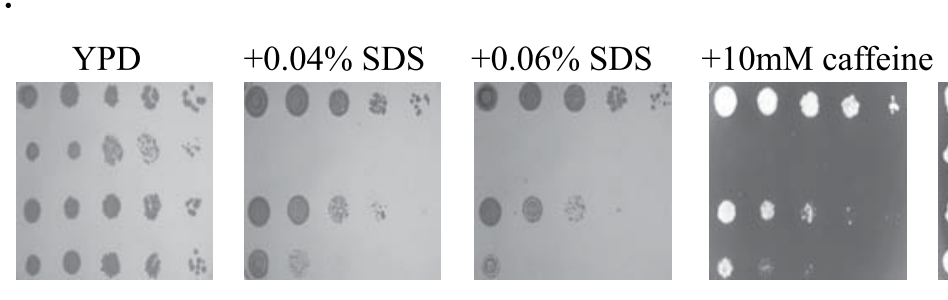

[ $1 \mathrm{M}$ sorbitol-

YPD $+10 \mathrm{mM}$ caffeine

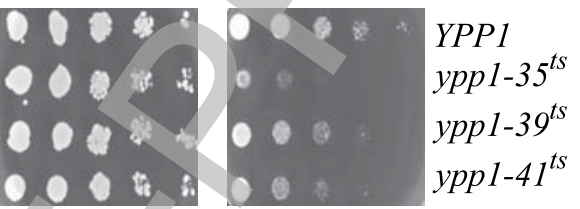


Figure 2
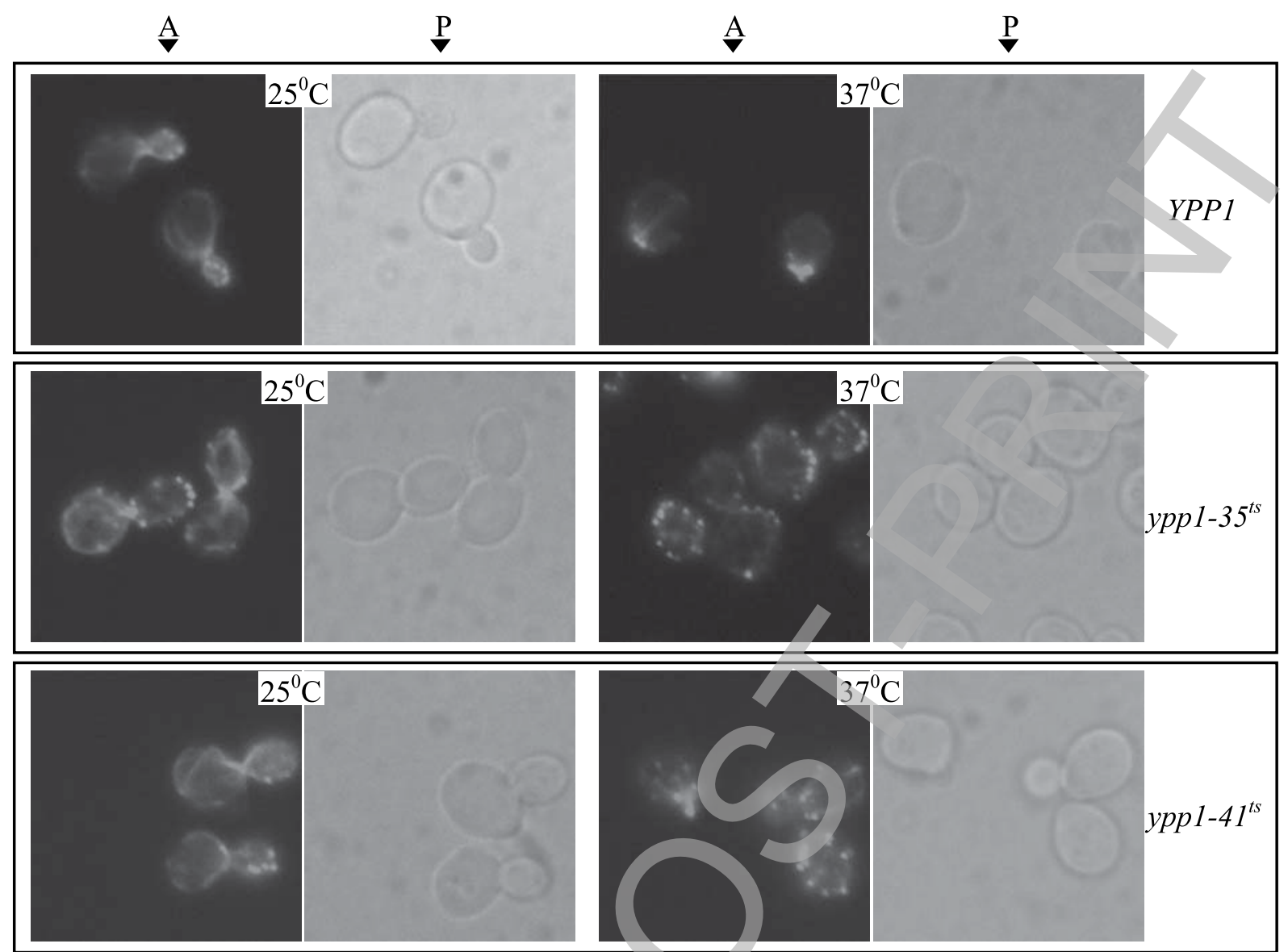

Licenced copy. Copying is not permitted, except with prior permission and as allowed by law. (C) 2008 The Authors Journal compilation (C) 2008 Biochemical Society 
Figure 3

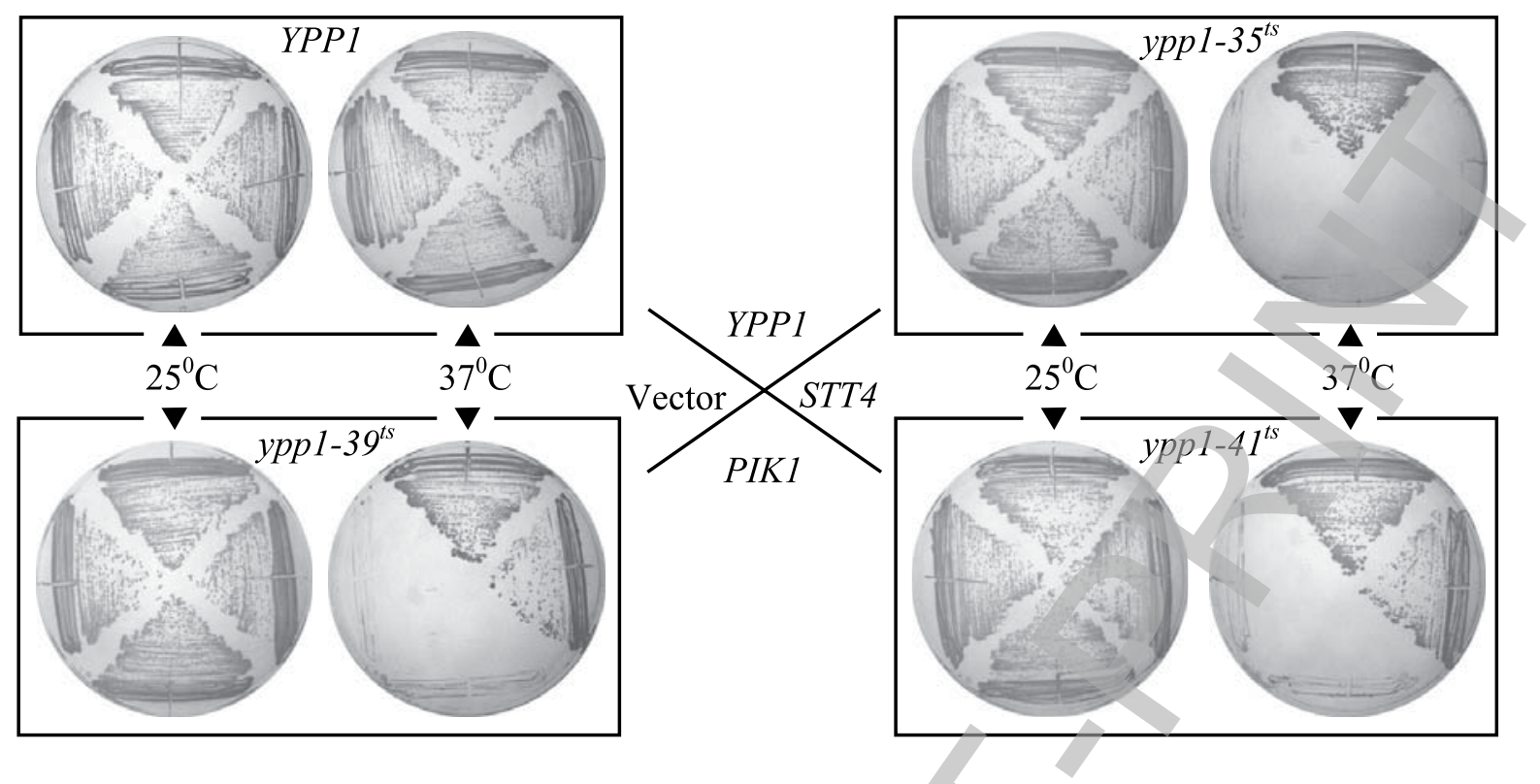


Figure 4
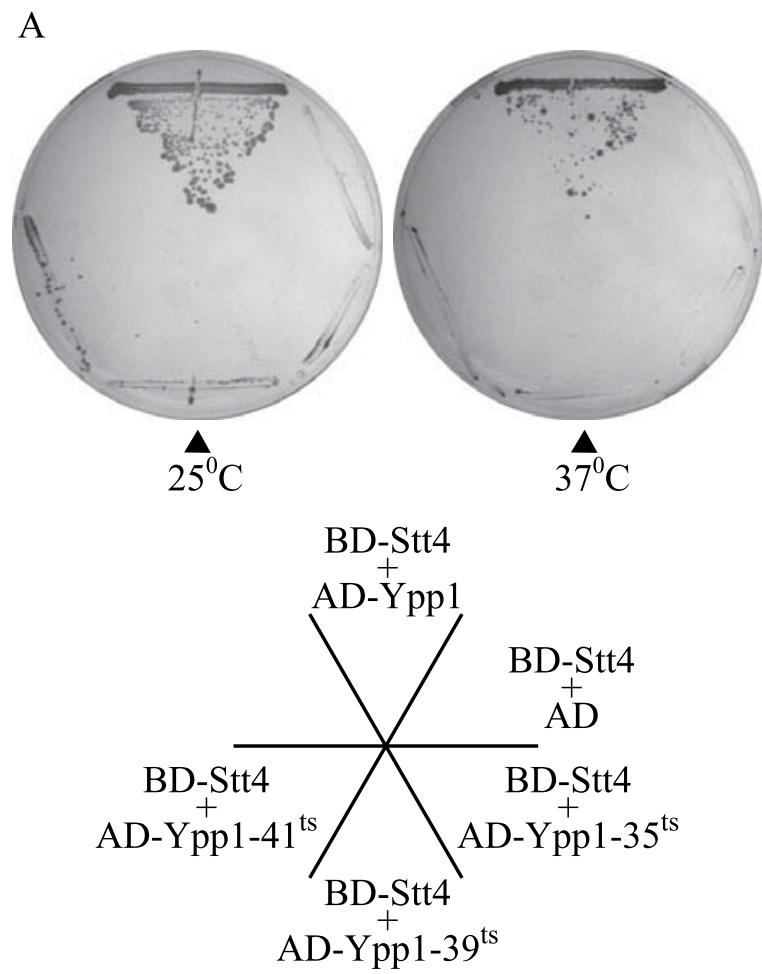

$\mathrm{B}$

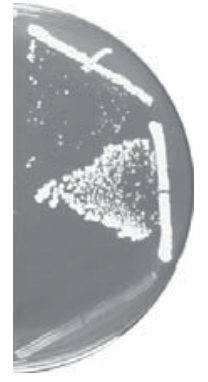

$\underset{25^{0} \mathrm{C}}{\overrightarrow{0}}$

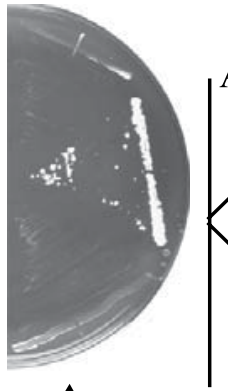

$37^{0} \mathrm{C}$
BD-Stt4

AD-Ypp1-30 ${ }^{\text {ts }}$

BD-Stt4

AD-Ỳpp1

BD-Stt4

AD 
Figure 5
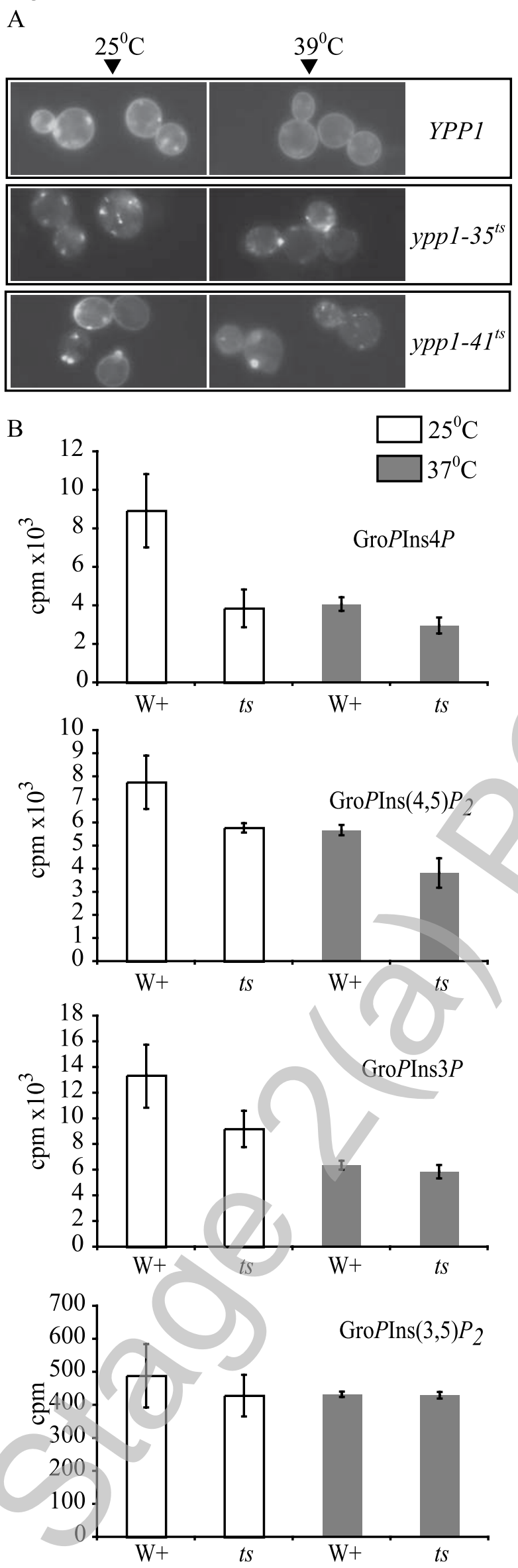
Figure 6

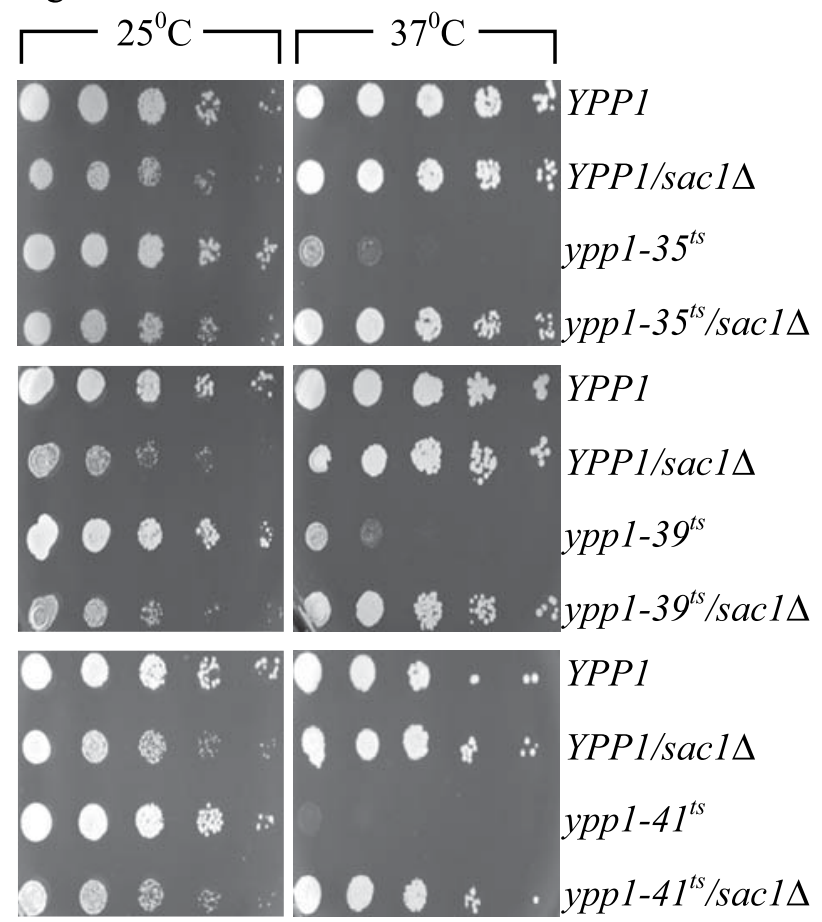


Figure 7

A
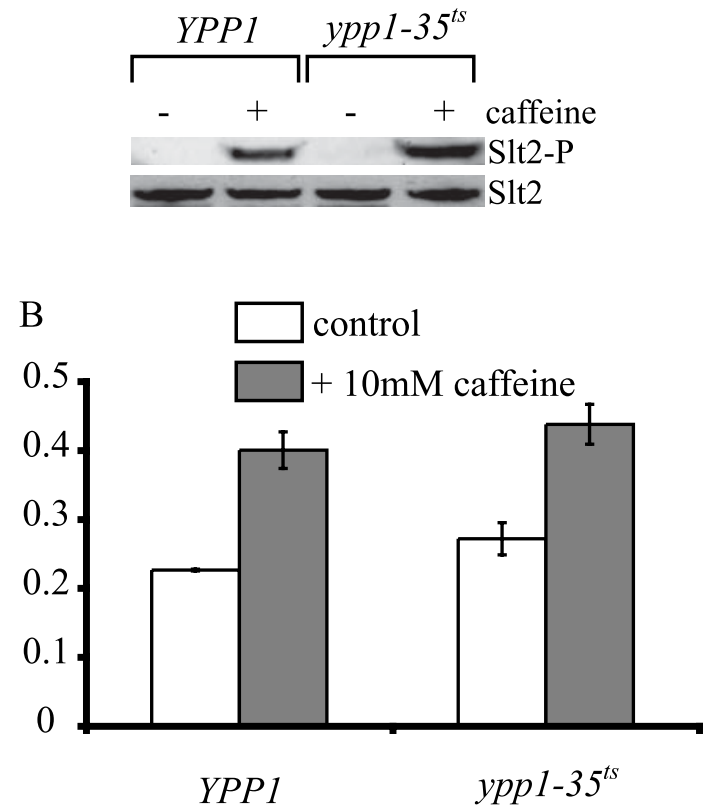
Figure 8

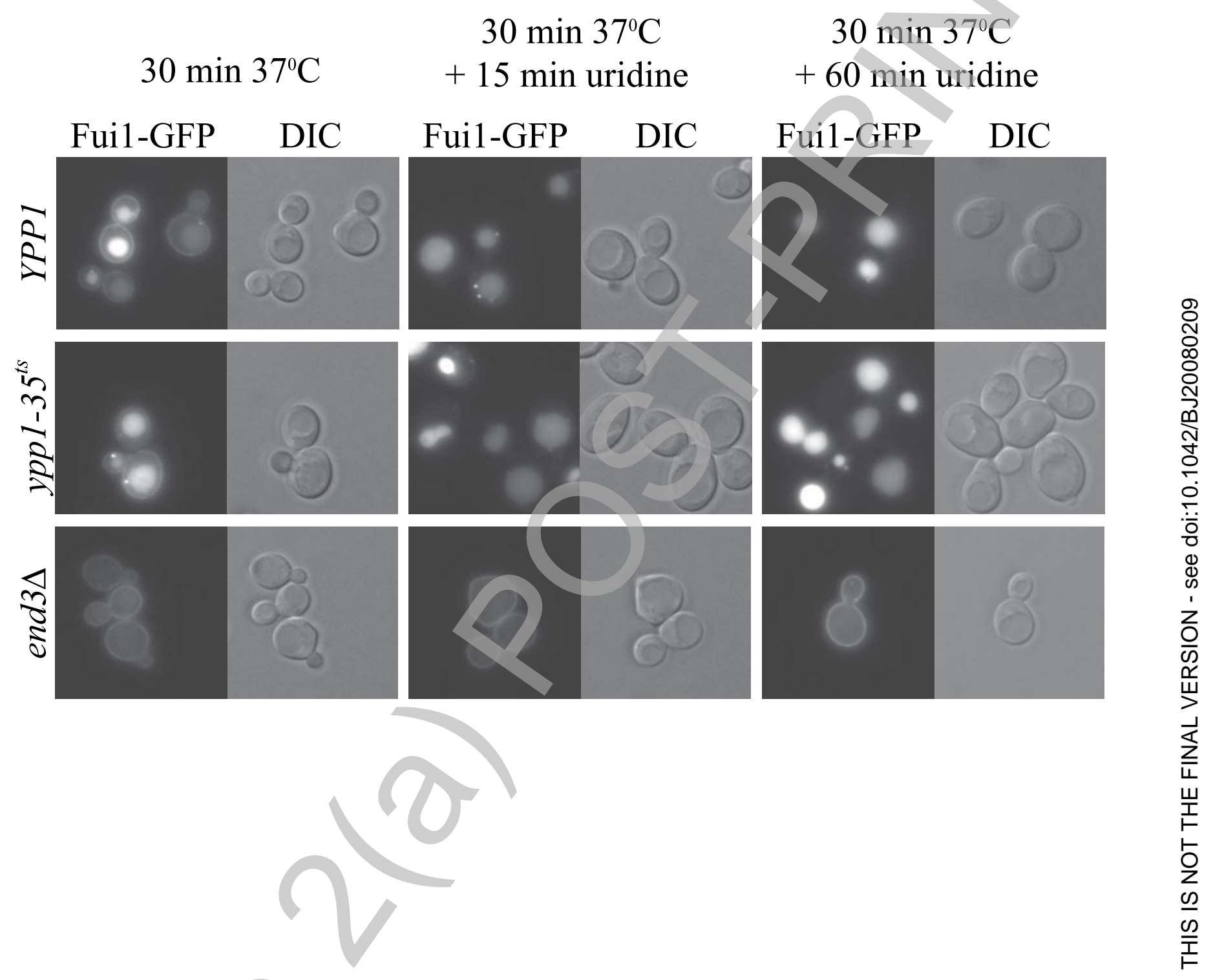


B Biochemical Journal Immediate Publication. Published on 04 Jul 2008 as manuscript BJ20080209

Figure 9

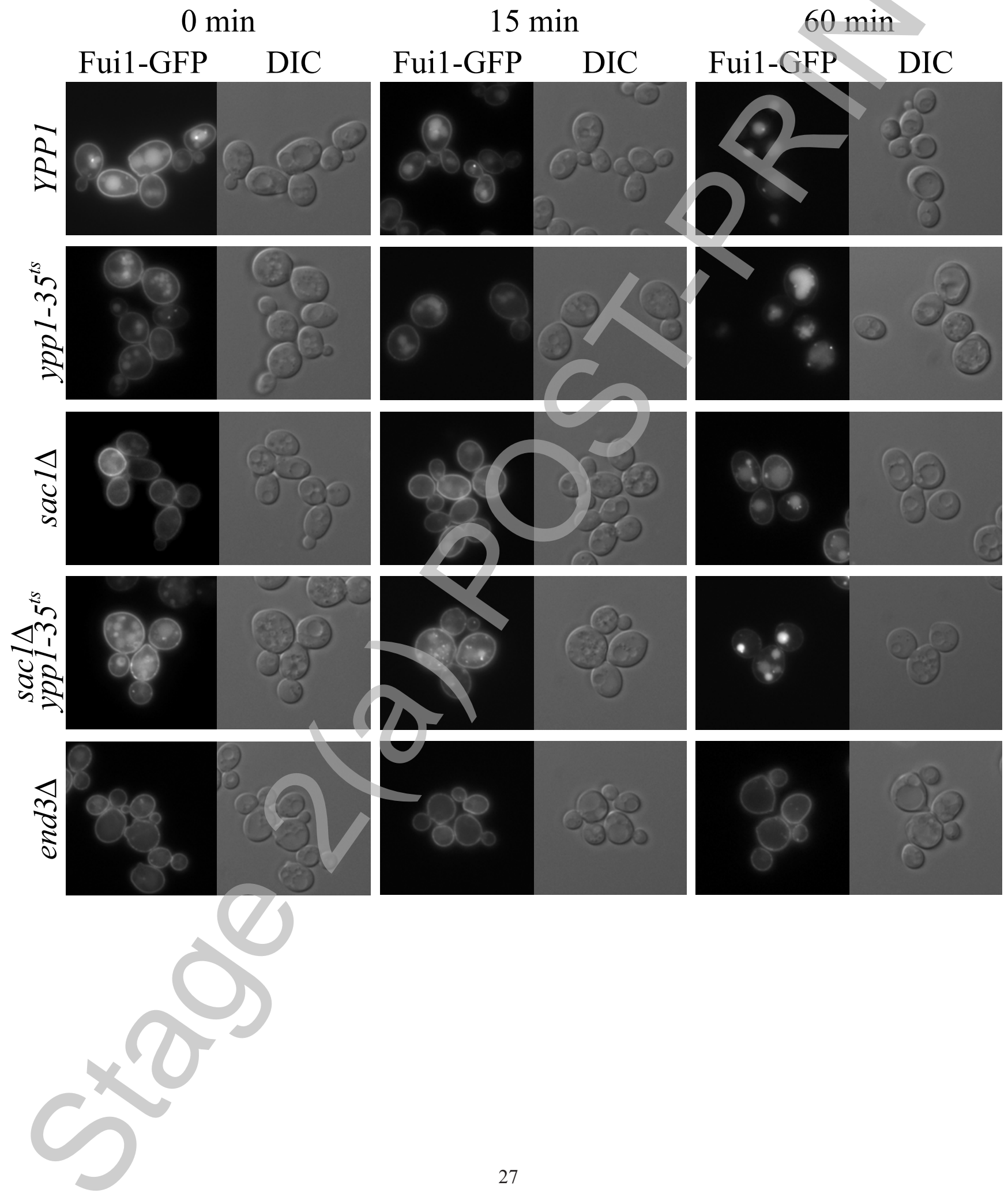

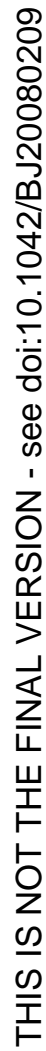

Licenced copy. Copying is not permitted, except with prior permission and as allowed by law. (C) 2008 The Authors Journal compilation (C) 2008 Biochemical Society 